\title{
Review
}

Annekathrin Haberland, Silvia Gilka Munoz Saravia, Gerd Wallukat, Reinhard Ziebig and Ingolf Schimke*

\section{Chronic Chagas disease: from basics to laboratory medicine}

\section{Abstract}

Chagas disease, caused by Trypanosoma cruzi infection, is ranked as the most serious parasitic disease in Latin America and has huge potential to become a worldwide problem, due to increasing migration, and international tourism, as well as infectant transfer by blood contact and transfusion, intrauterine transfer, and organ transplantation. Nearly $30 \%$ of chronically-infected patients become symptomatic, often with a latency of 10-30 years, developing life-threatening complications. Of those, nearly $90 \%$ develop Chagas heart disease, while the others manifest gastrointestinal disease and neuronal disorders. Besides interrupting the infection cycle and chemotherapeutic infectant elimination, starting therapy early in symptomatic patients is important for counteracting the disease. This would be essentially supported by optimized patient management, involving risk assessment, early diagnosis and monitoring of the disease and its treatment. From economic and logistic viewpoints, the tools of laboratory medicine should be especially able to guarantee this. After summarizing the basics of chronic Chagas disease, such as the epidemiological data, the pathogenetic mechanisms thought to drive symptomatic Chagas disease and also treatment options, we present tools of laboratory medicine that address patient diagnosis, risk assessment for becoming symptomatic and guidance, focusing on autoantibody estimation for risk assessment and heart marker measurement for patient guidance. In addition, increases in levels of inflammation and oxidative stress markers in chronic Chagas disease are discussed.

Keywords: autoantibodies; cardiac markers; Chagas cardiomyopathy; Chagas disease; inflammation marker; oxidative stress marker.

*Corresponding author: Ingolf Schimke, Pathobiochemie und Medizinische Chemie, Charité - Universitätsmedizin Berlin, Charité Platz 1, 10117 Berlin, Deutschland, Phone: +49 30 450513011, Fax: +49 30 450513011, E-mail: ingolf.schimke@charite.de
Annekathrin Haberland: Pathobiochemie und Medizinische Chemie, Charité - Universitätsmedizin Berlin, Berlin, Deutschland

Silvia Gilka Munoz Saravia: Pathobiochemie und Medizinische Chemie, Charité - Universitätsmedizin Berlin, Berlin, Deutschland Gerd Wallukat: Max-Delbrück-Centrum Berlin-Buch, Berlin, Deutschland

Reinhard Ziebig: Institut für Laboratoriumsmedizin, Charité Universitätsmedizin Berlin, Berlin, Deutschland

\section{Introduction}

Chagas disease, caused by infection by the flagellate protozoan Trypanosoma cruzi is the most serious parasitic disease in Latin America [1]. The disease was named in honor of the Brazilian physician Carlos Chagas (born in 1879 in Oliveira, died in 1934 in Rio de Janeiro) who discovered T. cruzi as the infecting agent in 1909.

Due to the establishment of life-threatening complications in nearly $30 \%$ of infected subjects, manifesting in the majority as Chagas heart disease, a minority of patients develop gastrointestinal disorders. There are also patients who present with both complications. Chagas disease is currently the major cause of morbidity and mortality in Latin America, enormously burdening economic resources and dramatically affecting patients' social and labor situations.

International migration processes have brought infected subjects from Latin America to the rest of the world, so Chagas disease is increasingly becoming a worldwide problem for healthcare systems. Consequently, to counteract Chagas disease in general and specifically the development of the life-threatening complications, early diagnosis and risk assessment for becoming symptomatic and optimal patient guidance are prerequisite. In this context, and from economic and logistic viewpoints, the tools of laboratory medicine should be able to guarantee this. In addition, prevention concepts and modern treatment strategies are also critical.

Here, the basics of chronic Chagas disease are summarized, such as the epidemiological data, pathogenetic mechanisms thought to drive the disease and treatment 
options. Furthermore, tools of laboratory medicine will be presented that address patient diagnosis, risk assessment for becoming symptomatic and guidance, focusing on autoantibody estimation for risk assessment and heart marker measurement for patient guidance. In addition, increases in levels of inflammation and oxidative stress markers in chronic Chagas disease are discussed.

\section{Basics of Chagas disease}

\section{Etiology and epidemiology}

Trypanosoma cruzi has been divided into two major lineages: T. cruzi I and T. cruzi II (with the latter also consisting of subgroups), which show differences in their regional distribution and pathogenic potency for cardiomyopathy and gastrointestinal diseases [2]. Based on a recent consensus meeting, it was recommended that $T$. cruzi strains should be referred to by six discrete typing units (T. cruzi I-VI) [3].

Trypanosoma cruzi exists in three morphological forms, which demonstrate different life cycle phases. The life cycle of T. cruzi involves stages in the digestive tract of triatomine bugs (secondary host) as the vector. As summarized in Table 1, among Triatominae, the genera of Triatoma infestans, Rhodnius prolixus, Triatoma brasiliensis and Panstrongylus megistus are of special importance for transmission of

\begin{tabular}{|c|c|}
\hline Infectants & $\begin{array}{l}\text { T. cruzi } \\
\text { [T. cruzi I, T. cruzi II (new typing: T. cruzi I-VI)] }\end{array}$ \\
\hline Vectors & $\begin{array}{l}\text { Triatomine bugs } \\
\text { (Predominantly Triatomina infectance, Rhodnius } \\
\text { prolixus, Triatoma dimidiata) }\end{array}$ \\
\hline $\begin{array}{l}\text { Wild mammal } \\
\text { reservoir } \\
\text { hosts }\end{array}$ & $\begin{array}{l}\text { More than } 180 \text { mammals predominantly: marsupi- } \\
\text { als (opossums), edentates (armadillos, sloths), } \\
\text { chiroptera (bats), rodents (mice, rats, squirrels, } \\
\text { porcupines, beavers, guinea pigs, hamsters), but } \\
\text { also apes, foxes, deer }\end{array}$ \\
\hline $\begin{array}{l}\text { Domestic and } \\
\text { peridomestic } \\
\text { mammal res- } \\
\text { ervoir hosts }\end{array}$ & $\begin{array}{l}\text { Humans, dogs, goat, cattle, sheep, guinea pigs, } \\
\text { cats, mice, rabbit, rats, pigs }\end{array}$ \\
\hline $\begin{array}{l}\text { Non-vector } \\
\text { routes of } T \text {. } \\
\text { cruzi transfer }\end{array}$ & $\begin{array}{l}\text { Blood transfusion, diaplacental transmission, } \\
\text { oral transmission by mother milk, transmission } \\
\text { by sexual contact (contact with menstrual blood, } \\
\text { injury during sex), organ transplantation, contact } \\
\text { with infected blood (accidental transmission), oral } \\
\text { transmission of contaminated food }\end{array}$ \\
\hline $\begin{array}{l}\text { T. cruzi dis- } \\
\text { persion }\end{array}$ & $\begin{array}{l}\text { Emigration of infected subjects, infection during } \\
\text { tourism, blood product trading }\end{array}$ \\
\hline Victims & Humans, dogs \\
\hline
\end{tabular}

Table 1 Trypanosoma cruzi basic information.
Chagas disease in endemic areas. Both the female and male triatomine bugs are able to transmit $T$. cruzi throughout their lifetimes (up to 2 years). Further stages run in the blood and tissue of mammals (reservoir hosts).

Recently, the WHO [1] listed more than 180 wild, domestic and peridomestic mammals which are important as reservoirs; among this group, marsupials, edentates and rodents, as well as pets and livestock are prominent. The infectious form of T. cruzi, also called the metacyclic trypomastigote form, circulates freely after entering the host and, in this stage, is open for immunological attack. However, the vulnerability towards immunological attack diminishes after colonization of the trypomastigotes in phagocytic and non-phagocytic cells of the host's tissues. The variety of cells which act as a reservoir for the parasite is large, although a clear tropism exists for muscular and neuronal cells. Of the muscle cells, those of the heart and skeleton, as well as smooth muscle cells are affected to a similar degree. After cell colonization, the trypomastigotes transform to amastigotes which are able to replicate. After re-transformation of amastigotes into infectious trypomastigotes, and following cell lysis, trypomastigotes enter the blood circulation. From human blood, as well as from any other mammalian blood contaminated with the trypomastigotes, the parasite can be taken up by the triatomine bug when it sucks blood. In the mid-gut of the bug, the trypomastigote transforms into the epimastigote form, which is better adapted for survival within the insect, meaning that it is again able to replicate. Epimastigotes re-transform in the hindgut of the bug into infectious trypomastigotes that are excreted with feces and enter humans and other mammals, thus continuing the vicious cycle of $T$. cruzi infection. Infectious feces of the bugs pass via the bite or other small wounds into human blood, but the parasite can also pass from the feces through intact mucous membranes, especially of the mouth and the eyes. The feces remain infectious for a long time, probably even when outside the bug. Consequently, infection via the ingestion of food contaminated with feces has been reported [4].

Due to triatomine bug cannibalism, T. cruzi can also be spread among populations. In contrast, birds and reptiles do not carry T. cruzi.

The risk area of vectorial $T$. cruzi transmission ranges from the south of the US to the north of Argentina. However, in the south of the US, only a very small number of vectorborne cases of infection have been reported [5]. Despite successful multinational initiatives for interrupting T. cruzi transmission in Latin America, it was estimated that, there were still 28 million people at risk and 15 million infected cases in 2006, and an annual incidence and mortality of 41,200 and 12,500 people, respectively [6]. 
Outside the endemic area, it was estimated that there are more than 300,000 infected people in the US, based on the immigrant population of 23 million Latin Americans and the known prevalence of $T$. cruzi-infected subjects in their countries of origin [7]. In Australia and Canada, with 85,000 and 157,000 immigrants, 3000 and 5000 people were estimated to be infected, respectively [8].

Europe is also not spared from Chagas disease [9], and it is increasingly being recognized as an emerging public health problem in European countries [10, 11]. Based on a recently published epidemiological study with data collection in nine European countries [12,13], which clearly indicated the impossibility "to identify all people at risk due to the lack of data stratified by endemic countries", there are more than three million migrants from endemic countries living in Europe, mostly in Spain, with about $1,750,000$ subjects, followed by the UK and Italy. The estimated number of infected people was 68,318-123,078 among the study population, which resulted in a prevalence of $2.0 \%-2.36 \%$. Clearly, the highest infection rate has been calculated for Spain, with 47,984-86,618 (prevalence $2.7 \%-4.9 \%$ ) infected individuals. In the other European countries that were studied, the prevalence ranged between $0.4 \%$ and $0.7 \%$ in the Netherlands and $2 \%-4.8 \%$ in Switzerland. However, in the remaining European countries the total number of infected individuals was much lower among European children adopted from endemic areas, with the prevalence of infection being calculated as $1.2 \%-2.4 \%$, indicating an infection rate of 474-919 individuals.

There is presently no indication of vector-borne T. cruzi transfer in Europe. However, Europe is colonized by different subfamilies of the triatomine bug, including species of the Triatominae subfamily. Among these, T. rubrofasciata is known to be a T. cruzi carrier in Latin America. However, as previously summarized [14], various species of flea, fly, bedbug, mosquito and lice have been suggested as possible candidates for T. cruzi transmission. Ticks (Ixodida), were seen as another potential vector for T. cruzi in Europe, as some tick subspecies can carry $T$. cruzi, but it has not yet been demonstrated that ticks are able to transfer T. cruzi to humans. Whether this situation will change in the existence of advancing climate shifts, as proposed for other infectious diseases, such as Dengue and Malaria, is presently still speculative [15].

Consequently, non-vector routes of T. cruzi transmission are clearly more important outside of the endemic areas, as also in the endemic countries, due to the increasing success of counteracting the vectorial T. cruzi transmission. Among the non-vector routes, vertical transmission by intrauterine parasite transfer is the most important [16].
For Europe, after the documentation of one case of T. cruzi transmission from a mother to child in Spain [17], a study was recently published stating that among 3839 pregnant women who migrated from Latin America living in the area of Madrid, 3.96\% were found to be positive for T. cruzi infection. Due to the high prevalence of T. cruzi infection in the country of origin, up to $11.4 \%$ of pregnant women who migrated from Bolivia were sero-positive for T. cruzi infection. Four cases of congenital transmission (2.6\%) were found, and all infected children were born to Bolivian mothers [18]. Consequently, initiatives for the implementation of screening programs for pregnant women at risk of T. cruzi infection have been suggested [19]. Congenital T. cruzi transmission has also been detected in Switzerland [20], and all cases were again seen in children born to Bolivian mothers.

Trypanosoma cruzi transmission by infected mother's milk or by milk contaminated with blood from papillary fissures has been described as cited in [21] but these appear to be rare events. The potential risk of $T$. cruzi transmission by transplantation of infected organs should be not neglected [22]. Transmission during sexual contact can also not be excluded.

Since unknown T. cruzi carriers can serve as blood donors, about 100 million people are at risk of infection via contaminated blood [23, 24]. Other groups at risk of T. cruzi infection are occupational groups, such as social and healthcare employees who could come into contact with the blood of infected subjects. Consequently, blood donor screening began in 2007 in the USA [25]. Since 2005, Spanish regulatory law [26] has required that all at-risk donors (people born in an endemic area, people whose mothers were native to an endemic area and people who have undergone blood transfusions in an endemic area) are screened for Chagas disease and excluded from donation in the case of positivity. International tourism could increasingly become another route for the worldwide spread of Chagas disease as recently demonstrated by an Italian traveler [27]. Altogether, the worsening problem concerning Chagas disease in Europe is now more frequently seen in other countries [10, 28, 29].

\section{From acute to chronic Chagas disease}

After infection with $T$. cruzi, based on some excellent reviews [30-33] and illustrated in Figure 1 [34], the acute stage of Chagas disease starts and lasts for some weeks or months. The acute stage can be symptomless or can present only mild clinical symptoms, such as fever, malaise and lymphadenopathy. The unspectacular presentation 


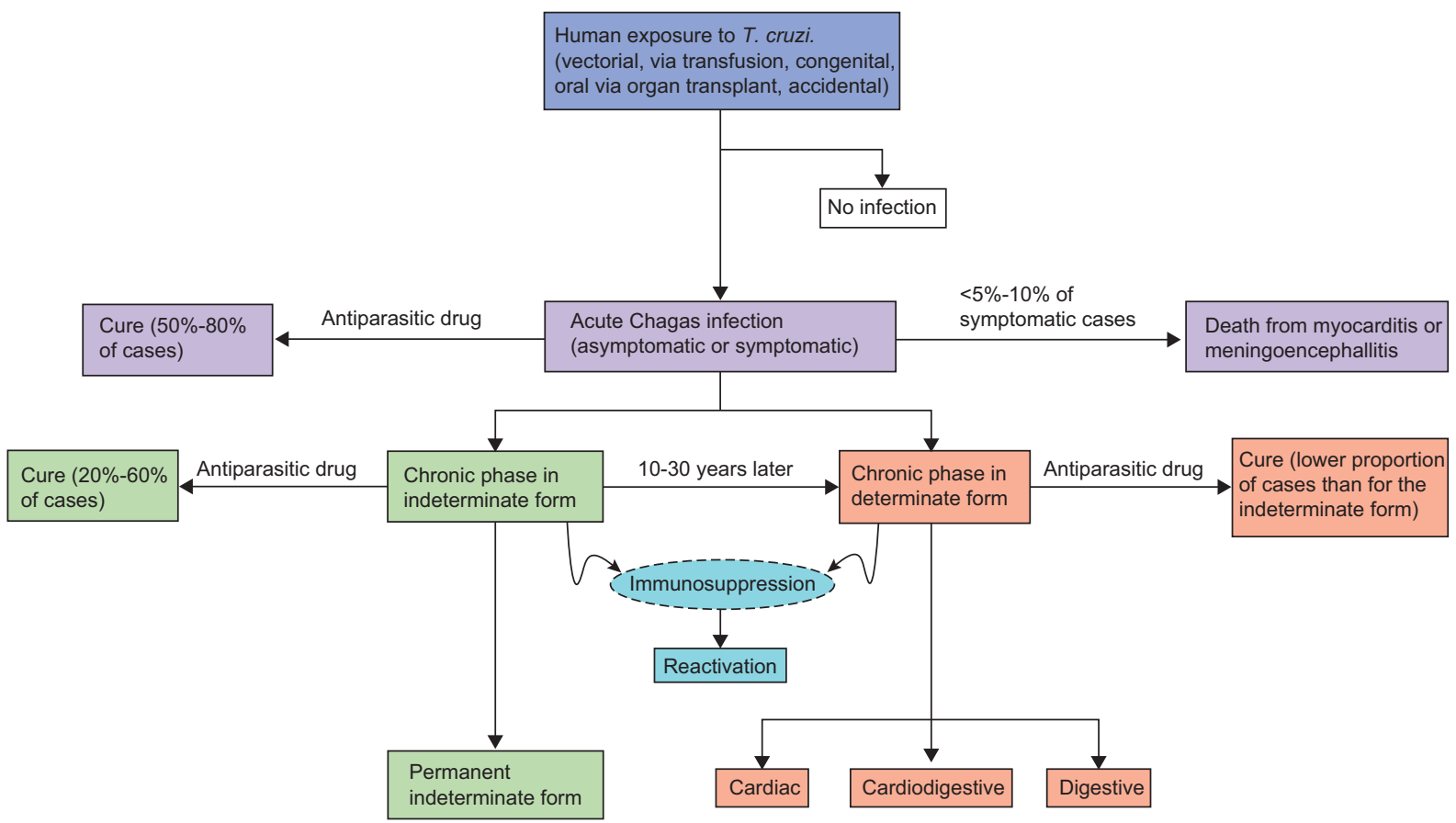

Figure 1 Natural history of Chagas disease in man.

From [34] with permission of Elsevier; license no. 2936990088001.

of the acute Chagas stage is seen as a result of parasite control by humoral and cellular immune responses and their cytokine-signaled interactions, as extensively reviewed [35-38]. However, their highly complex interactions are far from being clarified. Hepatosplenomegaly, myocarditis, and meningoencephalitis are only occasionally seen, and only in a small number of patients, especially children. The mortality rate due to acute Chagas disease is $2 \%-6 \%$, which is mainly through myocarditis and meningoencephalitis [39, 40]. In contrast, it seems that a host's defenses against $T$. cruzi can decrease over time, or that immune suppression elements that come directly from $T$. cruzi cause ineffective parasite control by the immune system. Both could contribute to incomplete parasite eradication, causing lifelong parasite persistence and resulting in chronically infected patients [41]. Consequently, the immune system in Chagas disease seems to clearly be a case of Dr. Jekyll and Mr. Hyde.

Due to the unspectacular acute stage, antiparasitic therapy is not often offered. Such therapy would clearly be helpful in the acute stage of the disease for parasite elimination. Without it, lifelong parasite persistence is maintained and the progression to chronic Chagas disease is favored. Fortunately, nearly $70 \%$ of chronically infected subjects remain in a clinically asymptomatic stage throughout their lives. Unfortunately, the other $30 \%$, frequently with a latency of decades, progress to symptomatic chronic Chagas disease, which is associated with the establishment of strong life-threatening complications in several cases. The heart is affected in nearly $90 \%$ of such cases, and these patients present cardiomyopathy associated with arrhythmias, heart failure and, frequently, sudden death. The remaining symptomatic patients suffer from gastrointestinal disorders, mainly manifested as mega-syndromes [42, 43], or neuronal disorders that are especially focused on the parasympathetic nervous system [44-46]. Some patients suffer from more than one complication.

Genetic variability has been discussed as being responsible [47] for whether patients remain asymptomatic or develop heart disease, gastrointestinal disease or neuronal disorders, but this debate has not yet been concluded [48]. Associations were observed between distinct HLA alleles and an increased risk of developing chronic Chagas disease in some studies [49,50], but others denied finding any such relationships [51].

\section{Chagas heart disease}

Chagas heart disease becomes manifest with a comparable frequency in both men and women, with no racial differences, and mainly starts between the ages of 30 and 50 years [52]. From the clinical point of view, 
chronic myocarditis, thromboembolic events, sudden cardiac death and congestive heart failure are typical of advanced Chagas heart disease. However, about 30\% of Chagas heart patients die from sudden cardiac arrest without any characteristic signs of advanced Chagas heart disease having been seen beforehand. The often apically aneurysmatic Chagas heart is thought to be the cause of thrombus formation, which may lead to thromboembolic events in the brain and lungs, and is thought to be responsible for the high rate of sudden death in Chagas heart disease. However, the main life-threatening complication of chronic Chagas disease is the continuous progression towards severe heart failure. Nearly $60 \%$ of patients die due to cardiomyopathy.

From an anatomical point of view, Chagas cardiomyopathy is characterized by progressive heart enlargement due to chamber dilatation. The walls and septum can become thickened, and can be combined with hypokinesia of the septum and the posterior wall. The histopathological features of the Chagas heart include typical signs of diffuse and patchy chronic myocarditis that are detected by nests of T-cells, varying numbers of B-cells and macrophages, diffuse interstitial fibrosis and a disturbed morphology of myocytes. The conduction system in the heart also shows alterations [53-55]. The microscopic detection of parasites in a chronic chagasic heart is only successful in 10\%-20\% of the patients tested. However, modern molecular diagnostic techniques using DNA amplification tests show the appearance of parasites in almost all patients with Chagas heart disease [56, 57].

In contrast, the severity of heart disease does not correlate with the occurrence of parasite DNA. This clearly indicates that direct heart damage in relation to parasite load and inflammation is not the only mechanism that must be considered. It is assumed that both the parasite and the host exert an influence on the pathogenesis of Chagas heart disease [58].

\section{Chagas gastrointestinal disease}

The gastrointestinal manifestations of chronic Chagas disease are mainly seen as megaesophagus, megacolon, megastomach, megaduodenum, megajejunum, megagallbladder and megacholedochus [42, 43]. Malnutrition caused by swallowing problems and regurgitation leading to weight loss, as well as obstipation accompanied by abdominal pain, mark the progress of chronic Chagas disease to megaesophagus and megacolon. Manometric investigation can be used to indicate abnormalities in the esophagus motility even in asymptomatic patients [43].
Symptomatic patients present with typical radiological signs. Radiological investigation employing barium as the contrast agent is the frequently used method for the diagnosis of megacolon. However, a simple radiological investigation is often sufficient. As in megaesophagus, manometric investigation to indicate early stages of megacolon can be helpful [43].

\section{The nervous system in chronic Chagas disease}

Damage to the parasympathetic nervous system may be one of the primary events in the pathogenesis of symptomatic Chagas disease and may contribute to heart and gastrointestinal Chagas disease in this way [44, 45]. It is assumed that the damage to the parasympathetic nervous system starts in the acute phase and proceeds into the chronic phase.

As summarized previously [59], the central nervous system is mostly affected during the acute phase of the disease and predominantly presents with encephalitis. Fever, headache, vomiting and seizures are typical characteristics. In chronic chagasic patients, the acute form can often be reactivated in cases of exogen- or endogeninitiated immunosuppression. The chronic nervous form of Chagas disease is seen as a consequence of the lesions that are initiated in the acute or reactive state of Chagas disease, and can present with histopathological findings of mild inflammation signs. However, most of the chronic chagasic patients have no profound signs of neurological alterations. Rare cases of changes in the psyche of chronically-infected Chagas patients are also a sign of nerve damage during the chronic phase of the disease.

More important neurological issues are stroke combined with brain atrophy and cognitive dysfunction following cerebral thromboembolic events in both asymptomatic or cardiac-symptomatic Chagas patients. Even asymptomatic patients, but more prominently chronic chagasic heart patients, may present arrhythmias, apical aneurysm and mural thrombus, all of which correlate with embolic strokes [60, 61]. A distinct number of patients with cerebral infarction secondary to Chagas disease present late vascular epilepsy as a complication.

\section{Pathogenesis of symptomatic chronic Chagas disease with special focus on Chagas heart disease}

Primary damage of the neuronal system, cell toxicity due to T. cruzi and/or T. cruzi-derived products, parasite-induced 
microvascular alterations, polyclonal B-cell activation, triggering of T-cell-mediated responses induced by persistent $T$. cruzi antigens and autoimmunity induced by T. cruzi-specific antigens or by the host antigen, have been proposed to drive the pathogenesis of symptomatic chronic Chagas disease [33, 35, 62-64]. Although pathogenic mechanisms have been analyzed with more detail in animal models and in patients with Chagas heart disease, which clearly mirror this disease's predominance in symptomatic Chagas patients, much of the data found in Chagas heart disease can also be used to explain aspects of the gastrointestinal and neuronal manifestations.

A multiple background for the pathogenesis of Chagas heart disease can be not ignored. There is, on the one hand, now clearly demonstrated by modern techniques (e.g., PCR) a life-long persistence of T. cruzi in the heart, which implicates more direct parasite-dependent damage mechanisms. This could be supported by immunological incompetence, among other mechanisms, importantly resulting from imbalances in regulatory T cells [38]. Consequently, reactivation of the parasite has been seen especially in HIV patients and also after transplantation [65, 66]. However, on the other hand, autoimmunity based on molecular mimicry and bystander activation has been increasingly seen as an important driver in the pathogenesis of symptomatic chronic Chagas disease [63]. It is known that T. cruzi proteins cross-react with proteins of the host's organs, which are then recognized by the host's activated immune system [63, 67]. However, the exact underlying mechanisms are far from being clarified.

Animal experiments focused on heart pathology [68] have clearly indicated that immunization with $T$. cruzi antigens, as well as the transfer of $T$. cruzi-activated $T$ cells, causes myocardial alterations, mainly focal myocarditis, demyelination and conduction system defects. Antigens, $\mathrm{T}$ cell clones and autoantibodies (AABs) found after infection with $T$. cruzi persist for a long time, which supports the autoimmunity theory of symptomatic chronic Chagas disease. In the context of autoimmunity, so-called functional AABs directed to G-protein-coupled receptors (GPCRs), such as AABs against the $\beta 1$-adrenergic ( $\beta 1$-AABs), $\beta 2$-adrenergic ( $\beta 2$-AABs) and muscarinergic2receptor (M2-AABs), were found in chronic chagasic patients and became increasingly important [68]. In one of our own studies, almost 100\% positivity was found for both $\beta 1-\mathrm{AABs}$ and M2-AABs, and $90 \%$ positivity for $\beta 2$ AABs in Chagas heart patients. Patients with gastrointestinal Chagas disease manifested with megacolon presented with nearly $100 \%$ positivity for $\beta 2$ - and M2-AABs. Only $38 \%$ of the megacolon patients were positive for $\beta 1-A A B s$, and nearly $100 \%$ of the patients who suffered both from chagasic heart and gastrointestinal disease were positive for all three AABs. In addition, positivity was also found for $\beta 1-A A B s, \beta 2-A A B s$, and M2-AABs in one third of all asymptomatic patients [70]. All three of these antibodies are agonistic. Depending on different downstream effects, e.g., the activation of adenylate cyclase by $\beta 1-\mathrm{AABs}$ and $\beta 2-\mathrm{AABs}$, and its inhibition by M2-AABs, positive or negative chronotropy are evident. In contrast to the physiological receptor agonists, typical defense mechanisms in the presence of agonist overload, such as receptor down-regulation, was missed for the functional AABs.

\section{G-protein-coupled receptors as autoantigens}

Originally demonstrated for $\beta 1$-AABs, but now also for M2-AABs and recently summarized [69, 71, 72], it is now well accepted that such autoantibodies are pathogenic substrates of cardiomyopathies and consequently also of Chagas heart disease. Among the underlying mechanisms which are activated by $\beta 1-A A B s$ and are heartpathogenic, are changes in action potential duration, altered Ca- and cAMP-dependent signal transduction associated with chronotropy and inotropy, and the stimulation of apoptosis. These mechanisms result in cardiomyopathy typical alterations, such as ultrastructural changes with focal myofibril lysis, the loss of normal myofilament banding patterns, the occurrence of hypercontraction bands, mitochondrial swelling and condensation, sarcoplasmic vacuolation, and the deposition of dense granules in both sarcoplasm and myofibrils [73]. For M2-AABs, decreased cAMP formation has been shown, whereas cGMP formation was increased, which supports a driving role of the parasympathetic nervous system. This could be responsible for the high incidence of atrial fibrillation in Chagas heart disease. In the gastrointestinal tract, M2-AABs inhibiting the parasympathetic nervous system were postulated to be responsible for reduced motility.

\section{Therapy}

Therapy in the acute stage, during reactivated infection and after congenital infection concentrates on the elimination of the parasites, preferably by using Nifurtimox or Benznidazol [34, 74-76]. While Nifurtimox has to be taken for between 50 and 120 days, Benznidazol is administrated for up to 60 days and, due to its safety and efficacy profile, is the first-line treatment option. 
However, some T. cruzi strains can develop resistance against these drugs, with only $50 \%$ of treated patients being drug responders. Furthermore, the existing drugs show enormous potential for toxic side effects, which manifest in the liver and as an allergic reaction, mainly after long-term administration.

The whole-genome sequencing of T. cruzi in 2005 revealed kinomes, which are known to contain a large and diverse set of protein kinases and phosphatases, and which could be used as targets in the future development of new, highly specific anti-T. cruzi drugs [77].

Anti-T. cruzi treatment can be offered to children and adults who do not have advanced Chagas heart disease, but it is contraindicated in pregnant women and subjects who suffer from kidney and liver insufficiency.

Due to the persistence of the PCR-detected myocardial parasite, its suggested role in the pathogenesis of chronic symptomatic Chagas disease, and animal experiments demonstrating the prevention of cardiomyopathy development following parasite reduction, a benefit of anti-T. cruzi treatment in the transition from the asymptomatic stage to the cardiomyopathic stage and further to severe cardiomyopathy was supposed but still remains to be found. "BENEFIT", which is an under-study multicenter trial on 3000 Latin Americans with mild to moderate Chagas heart disease, could clarify the relationship between trypanosomiasis interruption and cardiac disease progression and death [78].

After the manifestation of symptomatic Chagas disease, therapeutic possibilities are available that, in general, do not differ much from the treatment of cardiomyopathies $[79,80]$ and mega-syndromes of the gastrointestinal tract [43] of other etiologies.

With respect to the Chagas heart disease, drug treatment of heart failure, arrhythmias and thromboembolism, as well as pacemaker and cardioverter-defibrillator implantation and resynchronization therapy are clearly indicated.

Although $\beta$-blocker treatment in chronic Chagas cardiomyopathy has been critically viewed due to bradyarrhythmia and conduction defects, there is now evidence of its beneficial effects in Chagas cardiomyopathy patients [81, 82]. After the establishment of a cardioembolic risk score for chagasic patients, anticoagulation was recommended, in particular for cardioembolic stroke prophylaxis [83].

Irrespective of the continuous optimization of drug therapy, the outcome of chronic Chagas patients with severe heart failure is very poor, which is similar to the outcome seen for patients with heart failure due to other etiologies. One-year survival rates from $20 \%$ to $70 \%$ were documented [84, 85].
Heart transplantation [86] and assist device treatment for bridging until heart transplantation occurs, as well as destination therapy or bridging to recovery, are other options that have been tested [87]. As is the case for cardiomyopathy in general, cell-based therapy is being increasingly discussed for Chagas cardiomyopathy $[88,89]$.

Considering the increasing acceptance of an autoimmune background in the pathogenesis of symptomatic Chagas disease, new treatment regimens directed to the removal or specific inhibition of AABs, which are similar to those used in other diseases with autoimmune background, could become increasingly important. In this context, the elimination of pathogenetic AABs, such as the pathogenic $\beta 1-\mathrm{AABs}$, via apheresis techniques has been suggested for Chagas heart disease [90]. The idea of using apheresis in the treatment of Chagas heart disease is supported by the well-documented benefits of $\beta-1-A A B$ immunoadsorption in patients with DCM [91].

Last but not least [92-95], we recently reported results for the introduction of aptamers (for information about aptamers see [96]) as binders in the apheresis technique in order to clear plasma from the $\beta$-1-AABs found in Chagas heart patients. In addition, aptamers could also be suitable for the in vivo neutralization of $\beta 1$-AABs. This could offer a new strategy for the future treatment of patients with Chagas heart disease based on basics and a vision of aptamers future in cardiomyopathy treatment [97].

\section{Laboratory medicine in Chagas disease}

The detection of T. cruzi and/or anti-T. cruzi antibodies together with the use of conventional inflammation markers to diagnose Chagas disease and to guide asymptomatic patients is the unique job of laboratory medicine. In contrast, a black box for physicians is the assessment of the patient's risk of becoming symptomatic. No tools in cardiology, gastroenterology or neurology, or in laboratory medicine, can significantly assess this risk. For the early diagnosis of symptomatic Chagas disease, and guidance of these patients, the highly sophisticated methods as commonly applied in heart, gastrointestinal and neuronal diseases of other etiologies, are presently the firstline option. However, such methods are cost and labor intensive, depend on highly qualified staff, and are only available in special centers in endemic areas which are often, far from patients' homes. Therefore, these centers have important economic and logistical problems that are particularly relevant to their common use in endemic 
areas of Chagas disease. However, it is accepted that such problems could be of minor importance in developed countries. In contrast, laboratory medicine enables sampling to be performed where patients are situated and also enables the subsequent economic investigation of samples at highly specialized and automated centers that guarantee the highest quality service.

Consequently, tools of laboratory medicine should be tested for their use in monitoring the asymptomatic Chagas stage, but mainly in the risk assessment of asymptomatic patients, as well as their use in the diagnosis and monitoring of symptomatic Chagas disease.

\section{Parasite detection and anti-T. cruzi antibody test for diagnosis}

Trypanosoma cruzi in the circulating blood, especially at a high parasite titer which is predominantly observed in acute Chagas disease, can be directly detected by microscopic examinations of thick or thin blood films stained with Giemsa. Xenodiagnosis and hemoculture are classic indirect methods. During the chronic stage, because of the low blood parasite titer, direct and indirect parasite detection is more difficult and parasite enrichment using the Strout method or microhematocrit can be sometimes helpful in these cases.

Alternatively, PCR-based detection of parasitic DNA in blood and tissue samples can be performed [98, 99]. The PCR methods currently used are research tools and based on in-house developments. The methods are highly variable in their performance and are, in general, not supervised by a quality control system that is typically required in laboratory medicine. To bring the PCR detection of T. cruzi DNA nearer to laboratory medicine, a multi-center study has recently been conducted [100]. In this study, conventional and real-time PCRs were evaluated with respect to a pre-defined "Good Performing Method" using different $T$. cruzi DNA control materials (T. cruzi DNA in bi-distilled water, seronegative blood spiked with cultured T. cruzi and seropositive blood). Among the 48 tested PCRs, four of them were selected as being superior in their performance. However, as summarized from a systematic analysis of the literature, and in contrast to former recommendations of PCR use for immunoassay confirmation, "currently, PCR should not be used in clinical practice for chronic Chagas disease diagnostics and there is no PCR test commercially available for this purpose" [101]. Regardless of this, in-house PCR, if well-standardized and controlled, as well as performed by highly-qualified staff, is already an invaluable tool in Chagas parasite detection in our view, and will be even more so in the future.

During the acute phase of Chagas disease, antiT. cruzi antibodies of the IgM type can be detected [39, 102]. Chronic Chagas disease is most frequently diagnosed by the detection of IgG-type anti-T. cruzi antibodies, mainly by using ELISA, indirect hemagglutination, and indirect immunofluorescence. Initiated by the WHO [103], frequently used assays for the detection of anti-T. cruzi antibodies of the IgG type in chronic Chagas patients were compared in a multicentric study to assess the sensitivity and specificity of the assay. It was found that T. cruzi antibodies of the IgG type were detectable in hemagglutination assays (sensitivity $=88 \%-99 \%$, specificity $=96 \%-100 \%$ ), particle agglutination assays (97\%-100\%, 97\%-99.5\%), and ELISA (94\%-100\%, 96\%-100\%). Indirect immunofluorescence (sensitivity 98\%, specificity 98\%), Western blot (100\%, 100\%), immunoblot (98\%, 99.5\%), and radioimmunoprecipitation $(100 \%, 100 \%)$ confirmed the aforementioned results. Based on the data collected in this study, the authors summarized that some of the ELISA results showed excellent sensitivities and specificities and could be used for screening donated blood and blood products. In contrast, hemagglutination assays were not recommended for T. cruzi antibody detection, specifically for blood donor screening. WHO experts [1], and then later the FDA issued guidance entitled, "Use of serological tests to reduce the risk of transmission of Trypanosoma cruzi infection in whole blood and blood components intended for transfusion" [104] recommended one-timeblood testing for T. cruzi antibodies with a licensed immunoassay test. Presently, two tests are licensed by the FDA and possess EC marking for application in Europe: the Ortho T. cruzi ELISA Test System and the ABBOTT PRISM Chagas ChLIA. However, the "FDA intends to reevaluate the recommendation for one-time testing after reviewing the outcome of ongoing studies..." which would be in agreement with more restrictive regulation in endemic countries, such as in Brazil, which require a second test of a different technique for Chagas confirmation in blood donors who tested positively for $T$. cruzi antibodies with an immunoassay. In addition, for epidemiological surveys, the use of one test has been recommended, which in our view, although not explicitly stated, should be ELISA. For diagnosis, patient guidance, and the detection of transplacental and perinatal transmission, two different tests are recommended of which one should be PCR. This procedure should also concern the detection of transplantation-associated transmission, in our view.

With respect to cost, performance, and automation, immunoassays for anti-T. cruzi antibodies of the IgG type 
are presently seen as first-line tools in the diagnosis and guidance of chronic Chagas disease, although there is a co-existence of $T$. cruzi infected patients and those infected with Leishmaniasis parasites, as well as those who are carriers of the non-human pathogen Trypanosoma rangeli in endemic Chagas areas. Parasite-specific IgGs of these groups of subjects can cross-react with anti-T-cruzi IgGs in the immunoassays producing false-positive results. To overcome this problem, immunoassays based on recombinant antigens were developed. Indirect immunofluorecence is currently still the most frequently used test for the confirmation of ELISA results.

Indirect immunofluorescence has a sensitivity that is close to $99 \%$ but shows several disadvantages, such as the need for highly qualified and specialized technicians, limited sample throughput, problems in standardization and quality control and a low automation grade. After more and more overcoming of the start-up problems of PCR in diagnose or confirmation of the T. cruzi infection, this method could become the future first-line tool.

\section{Assessment of the asymptomatic Chagas patient's risk of becoming symptomatic}

A patient's genetic disposition and the genetic diversity of $T$. cruzi could potentially determine risk [105], but a heterogeneous picture exists for genetic predisposition so far. At the HLA level, HLA-DBR1-1503 has been reported to be found more often in Chagas cardiomyopathy patients compared to healthy controls [106]. In other studies, genetic polymorphisms have been most frequently studied, looking at proteins which are involved in the regulation of the inflammatory processes, as they accompany chronic Chagas disease [107-110]. All of the identified polymorphisms correlate to a certain extent with the occurrence of Chagas heart disease without showing exclusivity. For the future, it remains to be seen whether the combination of several distinct polymorphisms might increase the predictive value for cardiomyopathy risk. The same will be true for the increasing knowledge of the complex network of immunity, as well as for the identification of more myocardial genes that are specifically expressed in the chagasic heart [111]. All of these could possibly be utilized to develop laboratory medicine tools that can be used for risk assessment and/or the early diagnosis of Chagas heart disease. Modern platforms, such as mass spectrometric profiling of serum, have been used increasingly for the identification of novel serum markers in Chagas patients [112, 113]. Finding such markers in asymptomatic patients and the evaluation of their potential for risk assessment would be a future step.

A more current and hopeful strategy for risk assessment could, in our view, be based on screening for AABs in asymptomatic Chagas patients. Although AABs are seen as more general pathogenic drivers and are found in different pathologies [69], the detection of the AABs in individuals diagnosed as being T. cruzi-infected but asymptomatic patients could indicate their risk of developing Chagas heart and gastrointestinal disease. Recent findings of our group, suggest that nearly $30 \%$ of asymptomatic Chagas patients are AAB-positive, which clearly parallels the epidemiological data on the incidence of symptomatic Chagas disease in chronically infected patients, and could support such a risk assessment strategy, given it will prove to be a truly prognostic value. The first preliminary data was recently presented, which showed that the finding of AABs in asymptomatic patients could predict their risk of becoming symptomatic [114]. The use of the AABs, in particular M2-AABs, for risk assessment is also seen as a promising strategy by others [115]. However, in order to verify the strategy of $\mathrm{AAB}$ screening for risk assessment in asymptomatic Chagas patients, prospective studies enrolling broad cohorts are indispensable. At the present time, to the best of our knowledge, no other AABs found in Chagas patients have been tested for risk assessment.

A bioassay has mostly been used for measuring AABs [70]. In this assay, cultured neonatal rat cardiomyocytes are used as the substrate for AABs. The AABs are quantified by monitoring the chronotropic effects induced by the AAB-containing IgG fractions prepared from the patient's blood. The addition of specific antagonists enables a differentiation between $\beta 1-, \beta 2-$, and M2-AABs. The beating frequency measured in this bioassay, as an integral parameter of cell functionality, is an advantage as it corresponds to the concentration of AABs. Moreover, the bioassay also tests $\beta 1-\mathrm{AABs}, \beta 2-\mathrm{AABs}$ and M2-AABs simultaneously. However, the limitations of this bioassay include sophisticated assay standardization, a lack of adequate control materials and extensive turnaround times.

There are other cell-based AAB quantification methods that can be used, with one example being the quantification of $\beta 1-A A B$ via cAMP formation in cultured cells that were engineered to express the recombinant receptor protein for $\beta 1-A A B s$. The quantification of cAMP was then possible using RIA or ELISA technology. Quantifying the formation of cAMP using FRET technology might become important in the future [116].

Considering the time, cost and capacity of cell-based assays, the development of less costly but more practical, well-standardized and more universally available 
immmunoassays seems to be an essential prerequisite for $\mathrm{AAB}$ measurement. For $\mathrm{AAB}$ quantification, both ELISA and RIA tests exclusively use AAB binding to small peptides that are homologous to extracellular receptor epitopes recognized by the AABs. However, immunoassays do not differentiate between functionally active and inactive AABs, which might be one of the reasons for the discrepancies in the results between ELISA tests and the bioassays which use AAB functionality for quantification [117]. Nevertheless, ELISAs that were specific for $\beta 1-A A B s$, $\beta 2$-AABs and M2-AABs have been frequently used in different studies $[118,119]$. However, to the best of our knowledge, no immunoassay for Chagas disease relevant AABs against GPCR has been standardized according to the requirements of laboratory medicine and is commercially available at present.

To establish a new method for the AAB measurement, our selected aptamers $[92,95]$ could be potentially used as $\mathrm{AAB}$ binder in respective assays.

\section{Patient monitoring in acute and chronic Chagas disease}

For patient guidance in acute and chronic Chagas disease, and for monitoring the progress of the disease from asymptomatic to symptomatic by means of laboratory medicine tools, markers derived from: 1 ) the parasite background of the disease (T. cruzi products, anti-T. cruzi antibodies); 2) the autoimmunity-associated pathogenesis (AABs, as already discussed before); and 3) general pathways involved in the pathogenesis of symptomatic Chagas disease (inflammation, oxidative stress, organ specific functional and structural alteration), could be helpful.

In view of 1) Chagas disease progression, mainly from the asymptomatic stage to the stage of developing the lifethreatening complications, should involve the detection of the different stages in T. cruzi activity (e.g., the reactivation of the parasite) as the first-line strategy. As already indicated before and tested in clinical studies [120, 121], besides monitoring the $T$. cruzi antibody titer, the infectant detection and quantification by PCR will be the preferred method.

Many of the markers of 3) mainly those derived from inflammation and oxidative stress are non-specific. With respect to the organ-specific manifestation of chronic Chagas disease, markers which specifically indicate heart, gastrointestinal and neuronal alterations in the chagasic patient should be preferred. Unfortunately, there are no markers which are already established or currently being studied that could specifically be used for the detection of gastrointestinal and neuronal alterations in chronic Chagas patients.

In contrast, highly-specific heart markers, such as cardiac troponins and brain natriuretic peptide, are wellestablished laboratory medicine tools, which, in our view, could possess potential for the diagnosis and monitoring of patients with Chagas heart disease.

\section{Non-specific markers}

Regarding the impact of inflammatory processes on the pathogenesis of symptomatic Chagas disease, inflammation markers that are well-established in laboratory medicine should be appropriate, especially for disease and treatment monitoring. Based on the multiple roles of inflammation in the pathogenesis of Chagas disease [122], an increasing number of markers among chemokines, chemokine receptors, tumor necrosis factor, interferon gamma, constituents of prostaglandin, leucotriene and nitric oxide metabolism, platelet-activating factor, growth factors, matrix metalloproteinases and vasoactive compounds, such as Endothelin-1, could be potentially used for monitoring Chagas disease. Considering the tight connection between inflammation and oxidative stress, the measurement of markers of oxidative stress might also be helpful. Many of these markers (only a selection was referenced for demonstration) need to be tested in studies comparing asymptomatic patients and patients with Chagas heart disease, the last group due to a high prevalence among symptomatic patients.

\section{Inflammation markers}

The typical signs of inflammatory processes and immune responses are obvious, especially during the acute stage after infection with $T$. cruzi. Consequently, the measurement of cytokines and acute phase proteins could potentially be used to monitor acute Chagas disease in general and specifically during treatment $[123,124]$.

When acute phase proteins and the serological profiles of chagasic children were compared [125], only the early acute stage showed an increase in specific anti-T. cruzi IgM. The intermediate acute stage showed high levels of anti-T. cruzi IgM and/or anti-galactose antibodies (anti-Gal, which has been suggested to be an additional marker of the acute phase), as well as high levels of $\alpha_{2}$-macroglobulin and specific anti-T. cruzi IgG. Finally, in the late acute stage, the level of IgM decreased but $\alpha_{2}$-macroglobulin, CRP, anti-Gal and IgG levels were still high. In addition, increased $\alpha_{2}$-macroglobulin and 
CRP levels were shown when healthy controls and acute T. cruzi-infected children were compared [126].

For cytokines, such as TNF- $\alpha$, IL-2, IL-6, IL-8 and IL-12, and soluble receptors, such as sIL-2R, sCD8 and sCD4, Chagas disease-associated changes were reported, especially during the acute phase of infection [127-130]. The increased concentration of IL-2R agrees with findings in a mouse model, which showed that the expression of IL-2R was increased during immune suppression in the acute phase of infection.

Inflammation markers, such as CRP, are also increased in chronic chagasic patients when compared to healthy subjects, especially in those suffering from Chagas heart disease at an advanced stage. However, quite often the values found did not exceed the CRP cut-off used to diagnose acute inflammation [131].

In one of our own studies [132], when analyzing healthy controls and patients suffering from asymptomatic chronic Chagas disease or heart and gastrointestinal diseases, the levels of CRP and IL- 6 were significantly increased, mainly in the patient group suffering from heart disease. In this group, levels of both CRP and IL-6 were found to be above the inflammation-specific cut-offs in $41 \%$ and $71 \%$ of the patients, respectively. Additionally, CRP and IL-6 concentrations, and the percentage of patients with values above the cut-offs, increased with the severity of heart disease, which agrees with recently published data for CRP [133]. However, a distinct number of patients were also found in the asymptomatic and gastrointestinal groups in this study who presented with CRP and IL- 6 concentrations above the cut-offs.

Unfortunately, another study failed to demonstrate significant changes in the level of CRP in Chagas heart patients compared to healthy subjects and asymptomatic patients, although a more pronounced variability was found in the CRP values in symptomatic patients [134]. A recent study [135] comparing levels of CRP, which were measured using a highly sensitive assay in patients suffering from either chronic Chagas heart disease or from heart disease of another origin, demonstrated a slight CRP increase in parallel with the severity of cardiomyopathy, but without group-specific differences in view of the cardiomyopathy origin. It was suggested that patients with Chagas heart disease could be more affected by cytokine release than patients with idiopathic dilated cardiomyopathy. Although this was reflected by IL- 6 levels, the levels of TNF- $\alpha$ did not differ between the two groups of diseases. However, for both diseases, the markers were higher than in healthy subjects [136], and the level of IL-6 correlated with the outcome. For TNF- $\alpha$, comparable values, which were clearly higher than those for healthy subjects, were found in asymptomatic patients and in those with Chagas heart disease presenting left ventricular ejection fraction (LVEF) $>50 \%$. Patients with EVEF $<50 \%$ showed even higher values [137].

Recently, it was reported that the plasma levels of TNF superfamily ligands were increased in patients with functional, but not arrhythmogenic, disturbances, and that these death receptor ligands may be potential markers of ventricular dysfunction in chronic Chagas heart disease [138]. In addition to this, TNF- $\alpha$ levels related to the disease stage and differences in nitric oxide levels between healthy subjects and asymptomatic and symptomatic patients were also seen [139]. In contrast, differences in the concentration of TNF- $\alpha$ between healthy subjects and patients with mild cardiomyopathy were not always evident, whereas differences between mild and severe diseases were substantiated [140]. Patients who suffered from both HIV infection and Chagas disease presented with higher levels of TNF- $\alpha$ and IL- 6 compared with patients with HIV infection only [141].

Ex vivo stimulation with recombinant T. cruzi antigens of blood cells collected from Chagas patients was another approach tried for the differentiation of different disease stages [142, 143]. In this study, it was shown that the production of cytokines (mainly IFN- $\gamma$ and TNF- $\alpha$ ) increased relative to the chronic Chagas disease severity, especially for CD8+ T lymphocytes. It has also been demonstrated that anti-parasite treatment in chronic chagasic patients decreased the number of $T$. cruzi-specific IFN- $\gamma$ secreting T cells, using ex vivo measurements [144].

Summarizing this section, the acute disease stage can be detected by profound changes in the pattern of acute phase proteins and cytokines, which could be of interest as laboratory medicine tools for patient guidance at this stage of disease. Unfortunately, the data for acute phase protein and cytokine measurements in chronic Chagas disease are inconsistent. Consequently, the impact of these markers as laboratory medicine tools for the guidance of chronic Chagas patients is still restricted, especially for monitoring progression from the asymptomatic stage to the symptomatic stage.

\section{Markers of oxidative stress}

Oxidative stress has been defined as a metabolic condition that is characterized by imbalances in the equilibrium status of the pro- and anti-oxidant system in favor of pro-oxidant formation. In the case of pro-oxidant over production, these highly reactive molecules react with molecular structures in all major chemical classes found in living cells, realizing their toxic potential, and 
ultimately leading to cell death. Oxidative stress occurs in many pathophysiological situations including: hypoxia, hyperoxia, ischemia, inflammation and intoxication.

With respect to Chagas disease, oxidative stress produced during inflammation - as also seen in general - is needed for the host-innate immune response to control T. cruzi proliferation and phagocytosis. In cases of high T. cruzi titers and consequently overboarding inflammation, the excessive production of oxidative stress non-specifically damages various molecular and cellular structures leading to pathophysiological consequences. During oxidative stress in Chagas disease, a T. cruzi defense mechanism is induced which favors parasite intraphagosomal survival, escape to the cytosol and proliferation to increase virulence [145].

Mitochondrial damage in advanced Chagas heart disease, possibly resulting from hypoxic and ischemic conditions, has been suggested as a further source of excessive pro-oxidant generation [146, 147]. There are also indications that anti-parasite drug therapy in Chagas patients promotes oxidative stress which can be diminished by antioxidant co-treatment [148].

Treatment with antioxidant compounds prevented mitochondrial alterations in the heart of chagasic animals and reduced their pro-oxidant production [149]. Therefore, it is not surprising that oxidative stress has also been discussed as a general pathogenetic factor in heart failure [150], and especially in Chagas heart disease [151, 152]. Consequently, markers indicating increased oxidative stress $[153,154]$ were measured to demonstrate the impact of oxidative stress on Chagas disease, and it was found that anti-oxidant treatment can reduce oxidative stress in chagasic patients [155]. The first evidence of oxidative stress in Chagas disease came from animal experiments that indicated an increase in oxidative stress during the acute phase of $T$. cruzi infection. Increased oxidative stress in serum, especially in the heart, became visible via an increase in lipid peroxidation and protein carboxylation products. In parallel, a compensatory increase in antioxidant capacity was also observed. The acute infection was followed by a time of reduced oxidative stress.

However, the chronic stage of Chagas disease was again accompanied by increased oxidative stress alongside a reduction in antioxidant defense [156-159]. An increasing number of markers have been suggested as laboratory medicine tools for monitoring oxidative stress in humans. Among the oxidative stress markers $[153,154]$ myeloperoxidase is one that is applicable as a laboratory medicine tool in human studies. Myeloperoxidase, which is localized in neutrophil granulocytes, monocytes and tissue macrophages, is the molecular producer of hypochlorite, which is needed for parasite phagocytosis, but can be responsible for tissue damage when an excess is produced. In cases of the excessive stimulation of inflammatory cells, myeloperoxidase is released into the serum. In acute coronary syndrome and heart failure, the resulting serum levels of myeloperoxidase are of prognostic value [160]. Increased myeloperoxidase activity has also been observed in the serum of Chagas patients [161]. We, in contrast, did not find significant differences in the myeloperoxidase levels when comparing healthy subjects, asymptomatic Chagas patients and patients with chronic Chagas heart disease [162]. However, the greatest variation in the level of myeloperoxidase was seen in asymptomatic patients.

Other markers that have been used in human studies are products of lipid peroxidation, protein oxidation and protein nitration. The measurement of antioxidant defense compounds, such as anti-oxidant enzymes and non-enzymatic antioxidant compounds has also been used to assess oxidative stress in Chagas disease patients. It was recently shown that, compared to healthy controls, patients with chronic Chagas heart disease (NYHA I and II) presented with increased levels of oxidative stress, as indicated by an increase in levels of malone dialdehyde in the plasma [163], which was supported by our own findings of increased malon dialdehyde levels in asymptomatic Chagas patients and patients with heart disease [162].

The increased levels of oxidative stress correlated with mitochondrial dysfunction in Chagas patients [163]. In addition, lower blood activities of antioxidant enzymes (total superoxide dismutase, manganese superoxide dismutase and glutathione peroxidase) and a lower level of the non-enzymatic antioxidant glutathione have been found. A reduced antioxidant defense was also found in other studies $[164,165]$. A deficiency in selenium was also found in chronic Chagas patients, especially in those with progressed cardiomyopathy [166]. Although selenium is essential for glutathione peroxidase, which is one of the main constituents of the antioxidant defense system, the activity of this enzyme did not decrease in the chagasic patients of this study.

Recently, the over-expression of oxidative stress proteins has been indicated among T. cruzi isolates from patients with acute Chagas disease, which could be used as biomarkers of the clinical course of this disease [167, 168].

Summarizing this section, there are signs of oxidative stress in chagasic patients which could be reduced by anti-oxidant treatments, and both can be monitored with laboratory medicine tools. However, the results are 
inconsistent, which could result from the use of very different markers (different species of pro-oxidants, nonenzymatic and enzymatic anti-oxidative compounds, and different end-products of oxidative damage), which, consequently, mirror very different parts of the oxidative stress phenomenon. Furthermore, oxidative stress markers underlie some pre-analytic factors which cannot be very well handled. Last but not least, well-defined performance and standardization of these tests are missing in general.

\section{Heart-specific markers}

Abnormalities found in electrocardiography (ECG) and/ or echocardiography can be early indications of Chagas heart disease. In line with the diagnostic options available in endemic areas, cardiac arrhythmia found by ECG examination is often the first indication of chagasic cardiomyopathy in chronically-infected patients who, from an anamnestic and clinical viewpoint, are clearly thought to be in the asymptomatic stage [169]. Of the typical ECG abnormalities in chronic Chagas heart disease [170], right bundle branch block, left anterior hemiblock, ventricular extrasystoles, sinus bradycardia, auricular fibrillation and complete atrioventricular block are the most frequently found with increasing severity of the disease. For the evaluation of newly diagnosed patients with chronic Chagas disease based on T. cruzi antibody positivity [171], it was recommended that patients should undergo a medical history interview, a physical examination, and a resting 12-lead ECG with a 30-second lead rhythm strip and annual repetition in the case of normality. After diagnosing Chagas heart disease, a comprehensive cardiac evaluation is necessary, which should include a Holter ECG examination, echocardiography $[172,173]$ and exercise testing to differentiate coronary disease. MRT is also useful and can improve the diagnosis and management of chronic Chagas disease [174, 175].

In the last decade, highly-specific and sensitive cardiac markers, such as brain natriuretic peptides (BNP, NT-proBNP) and cardiac troponins (cTnT, cTnI), have been introduced in laboratory medicine and have been tested with regards to their potency to supplement or substitute the cardiologic diagnostics and monitoring of heart disease. Before the introduction of these highly-specific and sensitive cardiac markers, and despite very limited specificity, enzymes, such as AST, and later $\alpha \mathrm{HBDH}$, total CK and CK-MB, were widely accepted as blood markers for diagnosing myocardial damage, and especially damage related to ischemia and necrosis. However, due primarily to their insufficient sensitivity, these markers were not able to indicate myocardial alterations, such as focal inflammation and small disseminated necrosis in the chagasic heart. In two studies that addressed the problems of sensitivity and specificity by analyzing markers in blood samples obtained from the coronary sinus, superior cava vein and pulmonary artery, enzyme release, mainly of isocitrate dehydrogenase and $\alpha \mathrm{HBDH}$, was shown to be evident in Chagas heart patients [176, 177].

As in general for heart failure, markers indicating the progression of fibrosis and hypertrophy in the chagasic heart have been missed for a long time. However, typical changes in the enzymatic composition of the failing heart, e.g., shifts in the CK isoenzyme, are well-known [178], which could also be expected for the chagasic hypertrophic heart. However, to the best of our knowledge, no such data currently exists. Recently, a decrease in the level of the M-type CK protein was reported in the chagasic heart, as has also been found in cardiomyopathic hearts of other etiologies. This was combined with the loss of total CK activity in the heart, particularly in Chagas patients [179], but this shift in myocardial enzyme pattern is not expected to be mirrored in the blood, making it unusable for diagnostics.

To the best of our knowledge, no information currently exists concerning the presence of macroforms of heart enzymes (e.g., Macro-CK) in the serum of chronic chagasic heart patients that have also frequently been found in elderly and chronically diseased subjects, preferentially with an autoimmune background [180], that would be easily detected by electrophoretic techniques.

The currently preferred cardiac markers, based on analytical sensitivity and specificity, are natriuretic peptides for the detection of ventricular dysfunction and cardiac troponins to indicate ischemic-necrotic conditions in the heart. As a consequence, natriuretic peptides, preferably the brain natriuretic peptide with its marker BNP and NT-proBNP, are widely used for the diagnosis and monitoring of heart failure [181]. Therefore, it is not surprising that these markers are frequently analyzed in patients with Chagas heart disease.

The estimation of natriuretic peptides in Chagas disease patients began in 1994 with the measurement of the atrial natriuretic peptide in chagasic rats [182], followed in 2002 by its measurement in patients at different stages of Chagas disease [183]. In this study, the level of atrial natriuretic peptide in the blood clearly increased from asymptomatic to chronic heart-affected Chagas patients, with a further increase also reported at the 12 month follow-up.

As for heart failure in general, the plasma level of brain natriuretic peptide is the preferentially used indicator for ventricular dysfunction associated with chronic Chagas 
disease. In the first study to use this peptide as an indicator in 2002 [184], a cut-off was calculated that enabled chagasic patients to be screened for heart disorders via plasma BNP (cut-off of $60.7 \mathrm{pmol} / \mathrm{L}$, sensitivity and positive predictive value of $80 \%$, specificity and negative predictive value of $97 \%$ ). Following this study, a number of comparable studies were performed which clearly gave evidence that the plasma BNP level reflects the severity of Chagas heart disease [185-191]. In patients with chronic Chagas disease, e.g., characterized by LVEF $<40 \%$, the level of BNP was significantly higher than that in patients with LVEF $>40 \%$. The last patient group was not significantly different from the healthy controls [186], and the level of BNP was found to be negatively correlated with the LVEF. Based on a specific BNP cut-off, left ventricular dysfunction was detected with high sensitivity, specificity and negative predictive value in chronic chagasic patients. Recently, it was suggested that the combination of ECG and BNP is the best strategy for detecting left ventricular dysfunction in chronic Chagas patients [192], and that this combination is superior compared to the conventional strategy of ECG and chest X-ray. Regarding the economic and logistical situations in endemic areas, this laboratory medicine-based strategy was recommended as a first-line strategy for the recognition of LV dysfunction in Chagas disease.

A further finding regarding BNP in Chagas heart disease was that an increase in BNP is related to the 6 min walking distance [193]. However, no relationship was found with the level of BNP when the exercise capacity of Chagas heart patients was analyzed [194]. It was recently found that the level of BNP was correlated with diastolic dysfunction in chronic chagasic patients $[195,196]$.

Using end points, such as death and heart transplantation, the level of BNP can be used to predict the outcome of Chagas patients [192, 193]. Recently, the efficiency of BNP measurement in risk stratification was reported [197]. In this study, the prognostic value of BNP for allcause mortality among older adults with Chagas disease was found to be comparable to that of an ECG. Also, for the marker NT-pro-BNP, higher serum values and correlations with disease severity were shown in chagasic patients with heart disease [198-200], which is clearly in agreement with the results of our own study [162]. In this study, Chagas patients suffering only from heart failure or from heart failure combined with a gastrointestinal disorder were found to have significantly higher NT-proBNP levels than healthy subjects, patients with asymptomatic chronic Chagas disease and those with only a chagasic gastrointestinal disorder. Regarding the severity of chagasic heart disease, the level of NT-proBNP significantly increased from asymptomatic Chagas patients to patients with mild/moderate cardiomyopathy heart failure and again to patients with severe cardiomyopathy. In summary, clinical studies qualified brain natriuretic peptide measurements for severity differentiation in chronic chagasic heart patients mainly to demonstrate the progress from mild to severe cardiomyopathy which clearly point to the potential of brain natriuretic peptide measurements for patient guidance. However, significant trends for the increase of brain natriuretic peptides have been demonstrated when comparing the following patients: negative for Chagas disease vs. positive for Chagas disease without ECG and echocardiographic abnormalities, with typical ECG abnormalities but without echocardiographic abnormalities, and with typical echocardiographic indices for progressed cardiomyopathy, as well as if patients were separated due to normal diastolic function and dysfunction [196]. This shows that the measurement of brain natriuretic peptide could have potential for diagnostics in the early stage of chronic Chagas heart disease. However, in our view, a more sophisticated interpretation of the brain natriuretic peptide measurement (e.g., the comparison of patient values with age and gender related reference values) could force this.

The cardiac troponins I and $\mathrm{T}$ (cTnI; cTnT) have become the cornerstones in modern laboratory medicine for the diagnosis, risk stratification and therapy monitoring of patients with acute coronary syndrome [201]. However, there are numerous other physiological heart stressors, e.g., exercise [202], general pathologies affecting the heart [203] and cardiac diseases, such as stable angina, myocarditis, and heart failure [204, 205], all of which are accompanied by serum cardiac troponin values that are clearly different from those of healthy controls (although they may be below or near the established cut-off values for non-ST elevation infarction).

Many of the conditions associated with a mild cardiac troponin release and thought to be "non- or minimalnecrotic" in origin are associated with inflammation. This was recently shown for cardiac troponin release in runners [206].

Considering the focal inflammation and microlesions found in the chagasic heart, it was suggested that chronic Chagas patients with heart disease might present with increased levels of cardiac troponins in their blood. Only two previous studies and a single patient observation have analyzed cardiac troponin levels in Chagas heart disease [207-209], which unfortunately did not indicate a profound relationship between Chagas heart disease and cardiac troponin release, probably because of the insufficient sensitivity of the assays. However, the currently 
available, highly-sensitive cardiac troponin assays have now overcome this limitation. Using the highly sensitive cTnT assay for comparison of healthy controls, asymptomatic Chagas patients and patients with chagasic gastrointestinal disease, we found recently that chagasic heart patients present with increased $\mathrm{cTnT}$ concentrations in their blood, whereby the cTnT level raised from mild to severe cardiomyopathy [132]. This indicates that cardiac troponins, when measured using highly-sensitive assays, can be used in the guidance of Chagas patients.

Last, but not least, we suggest combining the measurement of brain natriuretic peptide in chronic Chagas patients with cardiac troponin measurements to improve the prediction of patients with heart disease among T. cruzi-infected subjects. However, this must be substantiated in future studies.

Summarizing this section, there is clear evidence that BNP/NT-proBNP alone, and probably better still in combination with cardiac troponins, can indicate heart alterations in Chagas patients. In this case, the tools of laboratory medicine are presently, especially in the diagnostics of the earliest heart alteration in chagasic patients, inferior compared to those of cardiologic diagnostics, mainly when echocardiography and MRT are used. With respect to cost and logistics, which prefer the use of heart markers when screening chronic Chagas patients, they seem to be well suited to increasing the pre-test probability of cardiologic diagnostics in chagasic patients.

\section{Conclusions}

Chagas disease, which is the most serious parasitic disease in Latin America, and which mainly manifests as Chagas heart disease, places an enormous burden on the economic resources of these countries and dramatically affects the social and employment status of Chagas patients. Due to the increasing migration of infected patients, intrauterine transfer and transfer via organ transplantation, international tourism, parasite transfer by transfusion and blood contact, Chagas heart disease is starting to become a major worldwide problem.

In order to counteract Chagas disease in general and specifically symptomatic Chagas disease presenting as heart, gastrointestinal and neuronal diseases, Chagas disease must first be accepted outside the endemic area as an important health problem. Second, mainly outside the endemic area, the knowledge regarding the disease basics, including etiology, epidemiological aspects, pathogenesis, and treatment options, must be increased. These must be combined with the establishment of optimal strategies

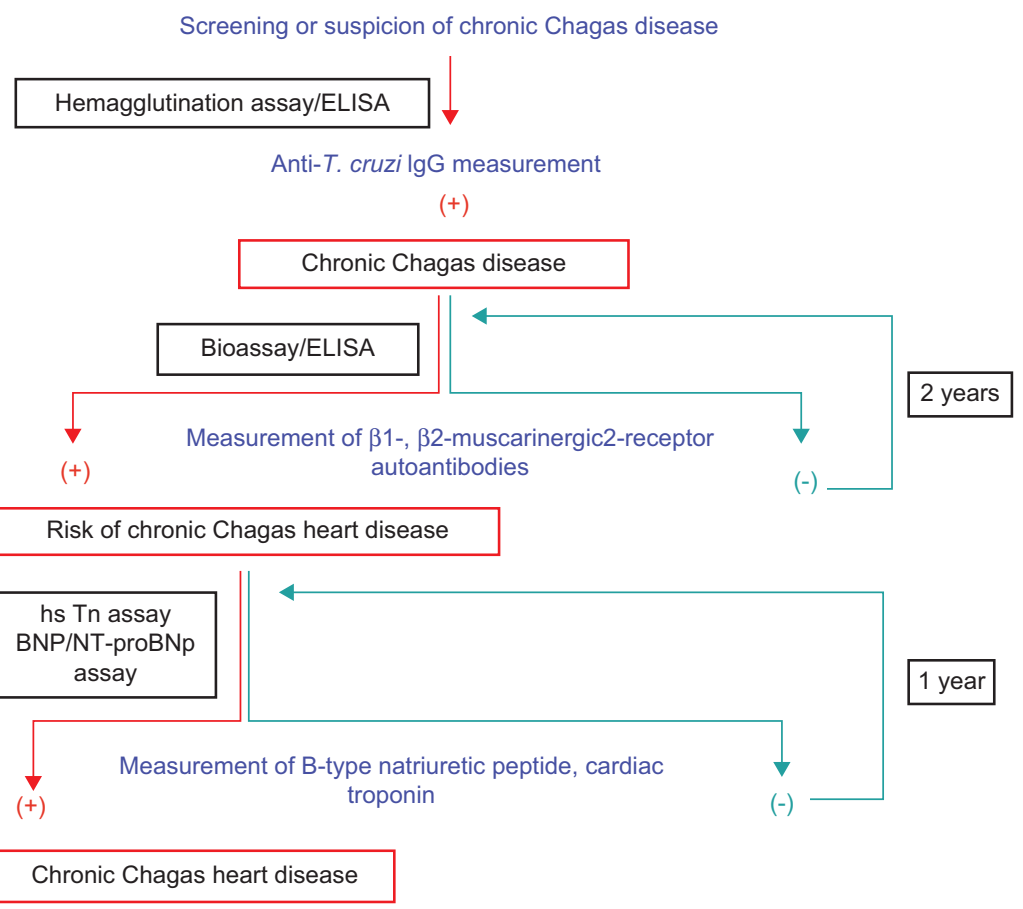

Figure 2 Suggested algorithm for combining autoantibody measurements and the measurements of B-type natriuretic peptide and cardiac troponins in chronic Chagas disease patients for risk assessment, diagnostics and monitoring. From [210], with permission of Springer; license no. 2910760939167. 
for the diagnosis of T. cruzi-infected patients, the development of programs to assess the patient's risk of becoming symptomatic, and if patients progress to symptomatic disease, for the early detection and monitoring of Chagas heart, gastrointestinal and neuronal disease.

In our view, such programs should include laboratory medicine tools, mainly as autoantibody measurements in asymptomatic Chagas patients for risk assessment, and the measurement of cardiac markers, such as brain natriuretic peptide and cardiac troponins for the diagnosis and monitoring of patients developing heart disease. An algorithm combining the measurement of AABs, B-type natriuretic peptide and cardiac troponins to support the fight against chronic Chagas heart disease by improved risk assessment, diagnosis and monitoring was recently suggested in [210] and is demonstrated here in Figure 2.
Acknowledgments: We are grateful to "Stiftung Pathobiochemie, Deutschen Gesellschaft für Klinische Chemie und Laboratoriumsmedizin" (66/2007 and 48/2011, Germany)" and "European Regional Development Fund" (10141685, Berlin, Germany)" for support.

\section{Conflict of interest statement}

Authors' conflict of interest disclosure: The authors stated that there are no conflicts of interest regarding the publication of this article. Research funding: None declared.

Employment or leadership: None declared.

Honorarium: None declared.

Received May 17, 2012; accepted August 15, 2012; previously published online October 6, 2012

\section{References}

1. WHO Expert Committee. Control of Chagas disease. World Health Organ Tech Rep Ser 2002;905:i-vi, 1-109.

2. Anonymous. Recommendations from a satellite meeting. Mem Inst Oswaldo Cruz 1999;94:429-32.

3. Zingales B, Andrade SG, Briones MR, Campbell DA, Chiari E, Fernandes 0 , et al. A new consensus for Trypanosoma cruzi intraspecific nomenclature: second revision meeting recommends Tcl to TcVI. Mem Inst Oswaldo Cruz 2009;104:1051-4.

4. Shikanai-Yasuda MA, Carvalho NB. Oral transmission of Chagas disease. Clin Infect Dis 2012;54:845-52.

5. Dorn PL, Perniciaro L, Yabsley MJ, Roellig DM, Balsamo G, Diaz J, et al. Autochthonous transmission of Trypanosoma cruzi, Louisiana. Emerg Infect Dis 2007;13:605-7.

6. Dias JC, Prata A, Correia D. Problems and perspectives for Chagas disease control: in search of realistic analysis. Rev Soc Bras Med Trop 2008;41:193-6.

7. Bern C, Montgomery SP. An estimate of the burden of Chagas disease in the United States. Clin Infect Dis 2009;49:e52-4.

8. Schmunis GA, Yadon ZE. Chagas disease: a Latin American health problem becoming a world health problem. Acta Trop 2010;115:14-21.

9. Guerri-Guttenberg RA, Grana DR, Ambrosio G, Milei J. Chagas cardiomyopathy: Europe is not spared! Eur Heart ] 2008;29:2587-91.

10. Guerri-Guttenberg RA, Ciannameo A, Di Girolamo C, Milei JJ. Chagas disease: an emerging public health problem in Italy? Infez Med 2009;17:5-13.

11. Société de pathologie exotique. Chagas disease. American trypanosomiasis. Recommendation for non-endemic zones. Med Trop (Mars) 2010;70:131-2.

12. Perez-Molina JA, Perez-Ayala A, Parola P, Jackson Y, Odolini S, Lopez-Velez R. EuroTravNet: imported Chagas disease in nine European countries, 2008 to 2009. Euro Surveill 2011; 16.pii:19966.
13. Basile L, Jansa JM, Carlier Y, Salamanca DD, Angheben A, Bartoloni A, et al. Chagas disease in European countries: the challenge of a surveillance system. Euro Surveill 2011; 16.pii:19968.

14. Dias JC, Schofield CJ, Machado EM, Fernandes AJ. Ticks, ivermectin, and experimental Chagas disease. Mem Inst Oswldo Cruz 2005;100:829-32.

15. Yacoub S, Kotit S, Yacoub MH. Disease appearance and evolution against a background of climate change and reduced resources. Philos Transact A Math Phys Eng Sci 2011;369: 1719-29.

16. Oliveira I, Torrico F, Muñoz J, Gascon J. Congenital transmission of Chagas disease: a clinical approach. Expert Rev Anti Infect Ther 2010;8:945-56.

17. Riera C, Guarro A, Kassab HE, Jorba JM, Castro M, Angrill R, et al. Congenital transmission of Trypanosoma cruzi in Europe (Spain): a case report. Am J Trop Med Hyg 2006;75:1078-81.

18. Flores-Chavez MD, Merino FJ, Garcia-Bujalance S, MartinRabadan P, Merino P, Garcia-Bermejo I, et al. Surveillance of Chagas disease in pregnant women in Madrid, Spain, from 2008 to 2010. Euro Surveill 2011;16.pii:19974.

19. Basile L, Oliveira I, Ciruela P, Plasencia A; Working Group for Developing the Catalonian Screening Programme for Congenital Transmission of Chagas Disease. The current screening programme for congenital transmission of Chagas disease in Catalonia Spain. Euro Surveill 2011;16.pii:19972.

20. Jackson Y, Chappuis F. Chagas disease in Switzerland: history and challenges. Euro Surveill 2011;16.pii:19963.

21. Ferreira CS, Martinho PC, Amato Neto V, Cruz RR. Pasteurization of human milk to prevent transmission of Chagas disease. Rev Inst Med Trop Sao Paulo 2001;43:161-2.

22. Chagas' Disease Argentine Collaborative Transplant Consortium, Casadei D. Chagas' disease and solid organ transplantation. Transplant Proc 2010;42:3354-9.

23. Schmunis GA. Risk of Chagas disease through transfusions in the Americans. Medicina (B Aires) 1999;59:125-34. 
24. Dias JC, Schofield CJ. The evolution of Chagas disease (American trypanosomiasis) control after 90 years since Carlos Chagas discovery. Men Inst Oswaldo Cruz 1999;94(Suppl 1):103-21.

25. Centers for Disease Control and Prevention (CDC). Blood donor screening for Chagas disease - United States, 2006-2007. MMWR Morb Mortal Wkly Rep 2007;56:141-3.

26. Real Decreto 1088/2005 por el que se establecen los requisitos técnicos y condiciones mínimas de la hemodonación y de los centros y servicios de transfusión del 20 de septiembre 2005 , núm. 225,31288-304.

27. Angheben A, Anselmi M, Gobbi F, Marocco S, Monteiro G, Buonfrate D, et al. Chagas disease in Italy: breaking an epidemiological silence. Euro Surveill 2011;16.pii:19969.

28. Sandahl K, Botero-Kleiven S, Hellgren U. Chagas' disease in Sweden - great need of guidelines for testing. Probably hundreds of seropositive cases, only a few known. Lakartidningen 2011;108:2368-71.

29. Salamanca-Dejour D, Blanchet D, Aznar C, La Ruche G, Jeannel D, Gastellu-Etchegorry M. Chagas disease (American trypanosomiasis) in France. Med Mal Infect 2012;42:344-8.

30. Biolo A, Ribeiro AL, Clausell N. Chagas disease: 100 years after its discovery. A systemic review. Acta Trop 2010;115:5-13.

31. Coura JR, Borges-Pereira J. Chagas disease. Lancet 2010;375:1388-402.

32. Lescure FX, Le Loup G, Freilij H, Develoux M, Paris L, Brutus L, et al. Chagas disease: changes in knowledge and management. Lancet Infect Dis 2010;10:556-70.

33. Teixeira AR, Hecht MM, Guimaro MC, Sousa AO, Nitz N. Pathogenesis of Chagas' disease: parasite persistence and autoimmunity. Clin Microbiol Rev 2011;24:592-630.

34. Rassi A Jr, Rassi A, Marin-Neto JA. Chagas disease. Lancet 2010;375:1388-402.

35. Gironés N, Cuervo H, Fresno M. Trypanosoma cruzi-induced molecular mimicry and Chagas' disease. Curr Top Microbiol Immunol 2005;296:89-123.

36. Dutra WO, Gollob KJ. Current concepts in immunoregulation and pathology of human Chagas disease. Curr Opin Infect Dis 2008;21:287-92.

37. Sathler-Avelar R, Vitelli-Avelar DM, Teixeira-Carvalho A, MartinsFilho $O A$. Innate immunity and regulatory T-cells in human Chagas disease: what must be understood? Mem Inst Oswaldo Cruz 2009;104(Suppl1):246-51.

38. de Araújo FF, Vitelli-Avelar DM, Teixeira-Carvalho A, Antas PR, Assis Silva Gomes J, Sathler-Avelar R, et al. Regulatory T cells phenotype in different clinical forms of Chagas' disease. PLoS Negl Trop Dis 2011;5:e992.

39. Moncayo A, Ortiz Yanine MI. An update on Chagas disease (human American trypanosomiasis). Ann Trop Med Parasitol 2006;100:663-77.

40. Ochs DE, Hnilica VS, Moser DR, Smith JK, Kirchhoff LV. Postmortem diagnosis of autochthonous acute chagasic myocarditis by polymerase chain reaction amplification of a species-specific DNA sequence of Trypanosoma cruzi. Am J Trop Med Hyg 1996;54:526-9.

41. Martin D, Tarleton R. Generation, specificity, and function of CD8+ T cells in Trypanosoma cruzi infection. Immunol Rev 2004;201:304-17.

42. Matsuda NM, Miller SM, Evora PR. The chronic gastrointestinal manifestations of Chagas disease. Clinics (Sao Paulo) 2009;64:219-24.
43. Pinazo MJ, Cañas E, Elizalde JI, García M, Gascón J, Gimeno F, et al. Diagnosis, management and treatment of chronic Chagas' gastrointestinal disease in areas where Trypanosoma cruzi infection is not endemic. Gastroenterol Hepatol 2010;33: 191-200.

44. Py M, Pedrosa R, Silveira J, Medeiros A, Andre C. Neurological manifestations in Chagas disease without cardiac dysfunction: correlation between dysfunction of the parasympathetic nervous system and white matter lesions in the brain. J Neuroimaging 2009;19:332-6.

45. Córdova E, Maiolo E, Corti M, Orduña T. Neurological manifestations of. Chagas' disease. Neurol Res 2010;32:238-44.

46. Chuenkova MV, Pereiraperrin M. Neurodegeneration and neuroregeneration in Chagas disease. Adv Parasitol 2011;76:195-233.

47. Andrade LO, Machado CR, Chiari E, Pena SD, Macedo AM. Trypanosoma cruzi: role of host genetic background in the differential tissue distribution of parasite clonal populations. Exp Parasitol 2002;100:269-75.

48. Tibayrenc M. Human genetic diversity and the epidemiology of parasitic and other transmissible diseases. Adv Parasitol 2007;64:377-462.

49. Layrisse Z, Fernandez MT, Montagnani S, Matos M, Balbas O, Herrera F, et al. HLA-C*03 is a risk factor for cardiomyopathy in Chagas disease. Human Immunol 2000;61:925-9.

50. Garcia Borras S, Racca L, Cotorruelo C, Biondi C, Beloscar J, Racca A. Distribution of HLA-DRB1 alleles in Argentinean patients with Chagas' disease cardiomyopathy. Immunol Invest 2009;38:268-75.

51. Faé KC, Drigo SA, Cunha-Neto E, Ianni B, Mady C, Kalil J, et al. HLA and b-myosin heavy chain do not influence susceptibility to Chagas' disease cardiomyopathy. Microbes Infect 2000;2: 745-51.

52. Kirchhoff LV. Chagas disease (American Trypanosomiasis). Available from: http://emedicine.medscape.com/ article/214581-overview. Accessed on 24 September 2012.

53. Tafuri WL, Maria TA, Lopes ER, Chapadeiro E. Electron microscopy of the myocardium in human Trypanosomiasis cruzi. Rev Inst Med Trop Sao Paulo 1973;15:347-70.

54. Rossi MA. Connective tissue skeleton in the normal left ventricle and in hypertensive left ventricular hypertrophy and chronic chagasic myocarditis. Med Sci Monit 2001;7:820-32.

55. Oliveira JS. A natural human model of intrinsic heart nervous system denervation: Chagas' cardiopathy. Am Heart J 1985;110:1092-8.

56. Braga MS, Lauria-Pires L, Argañaraz ER, Nascimento RJ, Teixeira AR. Persistent infections in chronic Chagas' disease patients treated with anti-Trypanosoma cruzi nitroderivatives. Rev Inst Med Trop Sao Paulo 2000;42:1561-71.

57. Lauria-Pires L, Braga MS, Vexenat AC, Nitz N, SimõesBarbosa A, Tinoco DL, et al. Progressive chronic Chagas heart disease ten years after treatment with anti-Trypanosoma cruzi nitroderivatives. Am J Trop Med Hyg 2000;63: 111-8.

58. Hernández-Becerril N, Nava A, Reyes PA, Monteón VM. IgG subclasses reactivity to Trypanosoma cruzi in chronic chagasic patients. Arch Cardiol Mex 2001;71:199-205.

59. Pittella JE. Central nervous system involvement in Chagas disease: a hundred-year-old history. Trans R Soc Trop Med Hyg 2009;103:973-8. 
60. Oliveira-Filho J. Stroke and brain atrophy inchronic Chagas disease patients. A new theory proposition. Dement Neuropsychol 2009;3:22-6.

61. Py MO. Neurologic manifestations of Chagas disease. Curr Neurol Neurosci Rep 2011;11:536-42.

62. Engman DM, Leon JS. Pathogenesis of Chagas heart disease: role of autoimmunity. Acta Trop 2002;81:123-32.

63. Bonney KM, Engman DM. Chagas heart disease pathogenesis: one mechanism or many? Curr Mol Med 2008;8:510-8.

64. Cunha-Neto E, Teixeira PC, Nogueira LG, Kalil J. Autoimmunity. Adv Parasitol 2011;76:129-52.

65. Pérez-Molina JA, Rodríguez-Guardado A, Soriano A, Pinazo MJ, Carrilero B, García-Rodríguez M, et al. Guidelines on the treatment of chronic coinfection by Trypanosoma cruzi and HIV outside endemic areas. HIV Clin Trials 2011;12:287-98.

66. Bern C. Chagas disease in the immunosuppressed host. Curr Opin Infect Dis 2012;25:450-7.

67. Cunha-Neto E, Bilate AM, Hyland KV, Fonseca SG, Kalil J, Engman DM. Induction of cardiac autoimmunity in Chagas heart disease: a case for molecular mimicry. Autoimmunity 2006;39:41-54.

68. Reis DD, Gazzinelli RT, Gazzinelli G, Colley DG. Antibodies to Trypanosoma cruzi express idiotypic patterns that can differentiate between patients with asymptomatic or severe Chagas' disease. J Immunol 1993;150:1611-8.

69. Xia Y, Kellems RE. Receptor-activating autoantibodies and disease: preeclampsia and beyond. Expert Rev Clin Immunol 2011;7:659-74.

70. Wallukat G, Muñoz Saravia SG, Haberland A, Bartel S, Araujo $R$, Valda $G$, et al. Distinct patterns of autoantibodies against G-protein-coupled receptors in Chagas' cardiomyopathy and megacolon. Their potential impact for early risk assessment in asymptomatic Chagas' patients. J Am Coll Cardiol 2010;55:463-8.

71. Yoshikawa T, Baba A, Nagatomo Y. Autoimmune mechanisms underlying dilated cardiomyopathy. Circ J 2009;73:602-7.

72. Dandel M, Wallukat G, Potapov E, Hetzer R. Role of b1-adrenoceptor autoantibodies in the pathogenesis of dilated cardiomyopathy. Immunobiology 2012;217:511-20.

73. Zuo L, Bao H, Tian J, Wang X, Zhang S, He Z, et al. Long-term active immunization with a synthetic peptide corresponding to the second extracellular loop of b1-adrenoceptor induces both morphological and functional cardiomyopathic changes in rats. Int J Cardiol 2011;149:89-94.

74. Garcia S, Ramos CO, Senra JF, Vilas-Boas F, Rodrigues MM, Campos-de-Carvalho AC, et al. Treatment with benznidazole during the chronic phase of experimental Chagas' disease decreases cardiac alterations. Antimicrob Agents Chemother 2005;49:1521-8.

75. Viotti R, Vigliano C, Lococo B, Alvarez MG, Petti M, Bertocchi $\mathrm{G}$, et al. Side effects of benznidazole as treatment in chronic Chagas disease: fears and realities. Expert Rev Anti Infect Ther 2009;7:157-63.

76. Kappagoda S, Singh U, Blackburn BG. Antiparasitic therapy. Mayo Clin Proc 2011;86:561-83.

77. El-Sayed NM, Myler PJ, Bartholomeu DC, Nilsson D, Aggarwal G, Tran AN, et al. The genome sequence of Trypanosoma cruzi, etiologic agent of Chagas disease. Science 2005;309:409-15.

78. Marian-Neto JA, Rassi A Jr, Morillo CA, Avezum A, Connolly SJ, Sosa-Estani S, et al. Rationale and design of a randomized placebo-controlled trial assessing the effects of etiologic treatment in Chagas' cardiomyopathy: the BENznidazole Evaluation For Interrupting Trypanosomiasis (BENEFIT). Am Heart J 2008;156:37-43.

79. Muratore CA, Baranchuk A. Current and emerging therapeutic options for the treatment of chronic chagasic cardiomyopathy. Vasc Health Risk Manag 2010;6:593-601.

80. Biolo A, Ribeiro AL, Clausell N. Chagas cardiomyopathy where do we stand after a hundred years? Prog Cardiovasc Dis 2010;52:300-16.

81. Botoni FA, Poole-Wilson PA, Ribeiro AL, Okonko DO, Oliveira $\mathrm{BM}$, Pinto AS, et al. A randomized trial of carvedilol after renin-angiotensin system inhibition in chronic Chagas cardiomyopathy. Am Heart J 2007;153:544.e1-8.

82. Issa VS, Amaral AF, Cruz FD, Ferreira SM, Guimarães GV, Chizzola $\mathrm{PR}$, et al. Beta-blocker therapy and mortality of patients with Chagas cardiomyopathy: a subanalysis of the REMADHE prospective trial. Circ Heart Fail 2010;3:82-8.

83. Sousa, Xavier SS, Freitas GR, Hasslocher-Moreno A. Prevention strategies of cardioembolic ischemic stroke in Chagas' disease. Arq Bras Cardiol 2008;91:306-10.

84. Mady C, Cardoso RH, Barretto AC, da Luz PL, Bellotti G, Pileggi F. Survival and predictors of survival in patients with congestive heart failure due to Chagas' cardiomyopathy. Circulation 1994;90:3098-102.

85. Bertolino ND, Villafanha DF, Cardinalli-Neto A, Cordeiro JA, Arcanjo MJ, Theodoropoulos TA, et al. Prognostic impact of Chagas' disease in patients awaiting heart transplantation. J Heart Lung Transplant 2010;29:449-53.

86. Campos SV, Strabelli TM, Amato Neto V, Silva CP, Bacal F, Boccia EA, et al. Risk factors for Chagas' disease reactivation after heart transplantation. J Heart Lung Transplant 2008;27:597-602.

87. Moreira LF, Galantier J, Benício A, Leirner AA, Cestari IA, Stolf NA. Left ventricular circulatory support as bridge to heart transplantation in Chagas' disease cardiomyopathy. Artif Organs 2007;31:253-8.

88. Vilas-Boas F, Feitosa GS, Soares MB, Mota A, Pinho-Filho JA, Almeida AJ, et al. Early results of bone marrow cell transplantation to the myocardium of patients with heart failure due to Chagas disease. Arq Bras Cardiol 2006;87:159-66.

89. Chachques JC. Cellular cardiac regenerative therapy in which patients? Expert Rev Cardiovasc Ther 2009;7:911-9.

90. Labovsky V, Smulski CR, Gómez K, Levy G, Levin MJ. Anti-beta1-adrenergic receptor autoantibodies in patients with chronic Chagas heart disease. Clin Exp Immunol 2007;148:440-9.

91. Dandel M, Wallukat G, Englert A, Lehmkuhl HB, Knosalla C, Hetzer R. Long-term benefits of immunoadsorption in $\beta 1$-adrenoreceptor autoantibody-positive transplant candidates with dilated cardiomyopathy. Eur J Heart Fail 2012; Aug 14 [Epub ahead of print].

92. Schimke I, Haberland A, Kage A, Wallukat G, Dahmen C. Aptamers that inhibit interaction between antibody and 2nd extracellular loop of human beta1-adrenergic receptor. Pub. No.: WO/2012/000889, International Application No.: PCT/ EP2011/06057; Publication Date: 05.01.2012, International Filing Date: 23.06.2011.

93. Haberland A, Wallukat G, Dahmen C, Kage A, Schimke I. Aptamer neutralization of beta1-adrenoceptor autoantibodies isolated from patients with cardiomyopathies. Circ Res 2011;109:986-92. 
94. Wallukat G, Haberland A, Berg S, Schulz A, Freyse EJ, Dahmen C, et al. The first aptamer-apheresis column specifically for clearing blood of beta1-receptor autoantibodies: a successful proof of principle using autoantibody positive SHR rats. Circ J 2012;76:2449-55.

95. Wallukat G, Haberland A, Schimke I. Use of aptamers in therapy and/or diagnosis of autoimmune diseases. EP 2497 828 A1, Application Number: 11157229.3; Date of Publication: 12.09.2012; Date of Filing: 07.03.2011.

96. Marquis JK, Grindel JM. Toxicological evaluation of oligonucleotide therapeutics. Curr Opin Mol Ther 2000;2:258-63.

97. Haberland A, Wallukat G, Schimke I. Aptamer binding and neutralization of $b(1)$-adrenoceptor autoantibodies: basics and a vision of its future in cardiomyopathy treatment. Trends Cardiovasc Med 2011;21:177-82.

98. Diaz C, Nussenzweig V, Gonzalez A. An improved polymerase chain reaction assay to detect Trypanosoma cruzi in blood. Am J Trop Med Hyg 1992;46:616-23.

99. Vago AR, Macedo AM, Adad SJ, Reis DD, Corrêa-Oliveira R. PCR detection of Trypanosoma cruzi DNA in oesophageal tissues of patients with chronic digestive Chagas' disease. Lancet 1996;348:891-2.

100. Schijman AG, Bisio M, Orellana L, Sued M, Duffy T, Mejia Jaramillo AM, et al. International study to evaluate PCR methods for detection of Trypanosoma cruzi DNA in blood samples from Chagas disease patients. PLoS Negl Trop Dis 2011;5:e931.

101. Brasil PE, De Castro L, Hasslocher-Moreno AM, Sangenis LH, Braga JU. ELISA versus PCR for diagnosis of chronic Chagas disease: systematic review and meta-analysis. BMC Infect Dis 2010;10:337.

102. Pinto AY, Valente SA, Valente Vda C, Ferreira Junior AG, Coura JR. Acute phase of Chagas disease in the Brazilian Amazon region: study of 233 cases from Pará, Amapá and Maranhão observed between 1988 and 2005. Rev Soc Bras Med Trop 2008;41:602-14.

103. Otani MM, Vinelli E, Kirchhoff LV, del Pozo A, Sands A, Vercauteren $\mathrm{G}$, et al. WHO comparative evaluation of serologic assays for Chagas disease. Transfusion 2009;49:1076-82.

104. FDA. "Guidance for industry: use of serological tests to reduce the risk of transmission of Trypanosoma cruzi infection in whole blood and blood components intended for transfusion". Available from: http://www.fda.gov/BiologicsBloodVaccines/ GuidanceComplianceRegulatoryInformation/Guidances/ Blood/ucm235855.htm. Accessed on 24 September 2012.

105. Campbell DA, Westenberger SJ, Sturm NR. The determinants of Chagas disease: connecting parasite and host genetics. Curr Mol Med 2004;4:549-62.

106. García Borrás S, Racca L, Cotorruelo C, Biondi C, Beloscar J, Racca A. Distribution of HLA-DRB1 alleles in Argentinean patients with Chagas' disease cardiomyopathy. Immunol Invest 2009;38:268-75.

107. Cruz-Robles D, Chávez-González JP, Cavazos-Quero MM, PérezMéndez O, Reyes PA, Vargas-Alarcón G. Association between IL-1B and IL-1RN gene polymorphisms and Chagas' disease development susceptibility. Immunol Invest 2009;38:231-9.

108. Ramasawmy R, Fae KC, Cunha-Neto E, Müller NG, Cavalcanti VL, Ferreira RC, et al. Polymorphisms in the gene for lymphotoxinalpha predispose to chronic Chagas cardiomyopathy. J Infect Dis 2007;196:1836-43.
109. Zafra G, Morillo C, Martín J, González A, González Cl. Polymorphism in the 3' UTR of the IL12B gene is associated with Chagas' disease cardiomyopathy. Microbes Infect 2007;9:1049-52.

110. Ramasawmy R, Cunha-Neto E, Fae KC, Martello FG, Müller NG, Cavalcanti VL, et al. The monocyte chemoattractant protein-1 gene polymorphism is associated with cardiomyopathy in human chagas disease. Clin Infect Dis 2006;43:305-11.

111. Cunha-Neto E, Teixeira PC, Fonseca SG, Bilate AM, Kalil J. Myocardial gene and protein expression profiles after autoimmune injury in Chagas' disease cardiomyopathy. Autoimmun Rev 2011;10:163-5.

112. Ndao M, Spithill TW, Caffrey R, Li H, Podust VN, Perichon R, et al. Identification of novel diagnostic serum biomarkers for Chagas' disease in asymptomatic subjects by mass spectrometric profiling. Clin Microbiol 2010;48:1139-49.

113. Ndao M. Biomarker discovery in serum/plasma using surface enhanced laser desorption ionization time of flight (SELDI-TOF) mass spectrometry. Methods Mol Biol 2012;818:67-79.

114. Muñoz Saravia SG, Haberland A, Bartel S, Araujo R, Valda G, Duchen $D$, et al. Distinct patterns of autoantibodies against G-protein coupled receptors in Chagas' cardiomyopathy and megacolon: their potential impact for early risk assessment in asymptomatic Chagas' patients. J Am Coll Cardiol 2010;56:526-7.

115. Goin JC, Borda E, Auger R, Storino R, Sterni-Borda L. Cardiac $M(2)$ muscarinic cholinoceptor activation by human chagasic autoantibodies: association with bradycardia. Heart 1999;82:273-8.

116. Nikolaev VO, Boivin V, Störk S, Angermann CE, Ertl G, Lohse MJ, et al. A novel fluorescence method for the rapid detection of functional beta1-adrenergic receptor autoantibodies in heart failure. J Am Coll Cardiol 2007;50:423-31.

117. Jahns R, Boivin V, Siegmund C, Inselmann G, Lohse MJ, Boege F. Autoantibodies activating human beta1-adrenergic receptors are associated with reduced cardiac function in chronic heart failure. Circulation 1999;99:649-54.

118. Limas CJ, Goldenberg IF, Limas C. Assessment of immune modulation of beta-adrenergic pathways in human dilated cardiomyopathy: influence of methodologic factors. Am Heart J 1992;123:967-70.

119. Del Corsso C, de Carvalho AC, Martino HF, Varanda WA. Sera from patients with idiopathic dilated cardiomyopathy decrease ICa in cardiomyocytes isolated from rabbits. Am J Physiol Heart Circ Physiol 2004;287:H1928-36.

120. Aguiar C, Batista AM, Pavan TB, Almeida EA, Guariento ME, Wanderley JS, et al. Serological profiles and evaluation of parasitaemia by PCR and blood culture in individuals chronically infected by Trypanosoma cruzi treated with benzonidazole. Trop Med Int Health 2012;17:368-73.

121. de Freitas VL, da Silva SC, Sartori AM, Bezerra RC, Westphalen EV, Molina TD, et al. Real-time PCR in HIV/Trypanosoma cruzi coinfection with and without Chagas disease reactivation: association with HIV viral load and CD4 level. PLoS Negl Trop Dis 2011;5:e1277.

122. Talvani A, Teixera MM. Inflammation and Chagas disease: some mechanisms and relevance. Adv Parasitol 2011;76:171-94.

123. Cervetta L, Moretti E, Basso B. Experimental Chagas' disease. The protection induced by immunization with Trypanosoma rangeli is associated with down-regulation of IL-6, TNF-a and IL-10 synthesis. Acta Parasitol 2002;47:73-8. 
124. Pakianathan DR, Kuhn RE. Interleukin-2 receptors in experimental Chagas' disease. Infect Immun 1992;60:3904-8.

125. Medrano-Mercado N, Luz MR, Torrico F, Tapia G, Van Leuven F, Araujo-Jorge TC. Acute-phase proteins and serologic profiles of chagasic children from an endemic area in Bolivia. Am J Trop Med Hyg 1996;54:154-61.

126. Medrano NM, Luz MR, Cabello PH, Tapia GT, Van Leuven F, AraújoJorge TC. Acute Chagas' disease: plasma levels of alpha-2-macroglobulin and C-reactive protein in children under 13 years in a high endemic area of Bolivia. J Trop Pediatr 1996;42:68-74.

127. Pascale JM, Sousa CE, Orn A. Evaluation of interleukin-2 soluble receptor in patients with tripanosomiasis Americana in Panama. Rev Med Panama 1991;16:184-8.

128. Pascale JM, Sousa OE, Orn A. Determination of soluble interleukin-2 receptor in patients with American trypanosomiasis in Panama. Rev Med Panama 1992;17:12-6.

129. Moretti E, Basso B, Cervetta L, Brigada A, Barbieri G. Patterns of cytokines and soluble cellular receptors in the sera of children with acute Chagas' disease. Clin Diagn Lab Immunol 2002;9:1324-7.

130. Ramasawmy R, Cunha-Neto E, Faé KC, Müller NG, Cavalcanti VL, Drigo SA, et al. BAT1, a putative anti-inflammatory gene, is associated with chronic Chagas cardiomyopathy. J Infect Dis 2006;93:1394-9.

131. López L, Arai K, Giménez E, Jiménez M, Pascuzo C, RodríguezBonfante $\mathrm{C}$, et al. C-reactive protein and interleukin- 6 serum levels increase as Chagas disease progresses towards cardiac failure. Rev Esp Cardiol 2006;59:50-6.

132. Saravia SG, Haberland A, Bartel S, Araujo R, Valda G, Reynaga $D D$, et al. Cardiac troponin T measured with a highly sensitive assay for diagnosis and monitoring of heart injury in chronic Chagas' disease. Arch Pathol Lab Med 2011;135:243-8.

133. Aparecida da Silva C, Fattori A, Sousa AL, Mazon SB, Monte Alegre $\mathrm{S}$, Almeida EA, et al. Determining the $\mathrm{C}$-reactive protein level in patients with different clinical forms of chagas disease. Rev Esp Cardiol 2010;63:1096-9.

134. Cetron MS, Basilio FP, Moraes AP, Sousa AQ, Paes JN, Kahn SJ, et al. Humoral and cellular immune response of adults from northeastern Brazil with chronic Trypanosoma cruzi infection: depressed cellular immune response to T. cruzi antigen among Chagas' disease patients with symptomatic versus indeterminate infection. Am J Trop Med Hyg 1993;49:370-82.

135. Melo LM, Souza GE, Valim LR, Moreira LF, Damico EA, Rocha TR, et al. Study of pro-thrombotic and pro-inflammatory factors in Chagas cardiomyopathy. Arq Bras Cardiol 2010;95:655-62.

136. Mocelin AO, Issa VS, Bacal F, Guimarães GV, Cunha E, Bocchi $E A$. The influence of aetiology on inflammatory and neurohumoral activation in patients with severe heart failure: a prospective study comparing Chagas' heart disease and idiopathic dilated cardiomyopathy. Eur J Heart Fail 2005;7:869-73.

137. Ferreira RC, Ianni BM, Abel LC, Buck P, Mady C, Kalil J, et al. Increased plasma levels of tumor necrosis factor-alpha in asymp tomatic/"indeterminate" and Chagas disease cardiomyopathy patients. Mem Inst Oswaldo Cruz 2003;98:407-11.

138. Lula JF, Rocha MO, Nunes Mdo C, Ribeiro AL, Teixeira MM, Bahia MT, et al. Plasma concentrations of tumour necrosis factor-alpha, tumour necrosis factor-related apoptosisinducing ligand, and FasLigand/CD95L in patients with Chagas cardiomyopathy correlate with left ventricular dysfunction. Eur J Heart Fail 2009;11:825-31.
139. Pérez-Fuentes R, López-Colombo A, Ordóñez-Toquero G, Gomez-Albino I, Ramos J, Torres-Rasgado E, et al. Correlation of the serum concentrations of tumour necrosis factor and nitric oxide with disease severity in chronic Chagas disease (American trypanosomiasis). Ann Trop Med Parasitol 2007;101:123-32.

140. Talvani A, Rocha MO, Barcelos LS, Gomes YM, Ribeiro AL, Teixeira MM. Elevated concentrations of CCL2 and tumor necrosis factor-alpha in chagasic cardiomyopathy. Clin Infect Dis 2004;38:943-50.

141. Rodrigues DB, Correia D, Marra MD, Giraldo LE, Lages-Silva E, Silva-Vergara ML, et al. Cytokine serum levels in patients infected by human immunodeficiency virus with and without Trypanosoma cruzi coinfection. Rev Soc Bras Med Trop 2005;38:483-7.

142. Lorena VM, Lorena IM, Braz SC, Melo AS, Melo MF, Melo MG, et al. Cytokine levels in serious cardiopathy of Chagas disease after in vitro stimulation with recombinant antigens from Trypanosoma cruzi. Scand J Immunol 2010;72:529-39.

143. de Melo AS, de Lorena VM, de Moura Braz SC, Docena C, de Miranda Gomes Y. IL-10 and IFN-g gene expression in chronic Chagas disease patients after in vitro stimulation with recombinant antigens of Trypanosoma cruzi. Cytokine 2012;58: 207-12.

144. Laucella SA, Mazliah DP, Bertocchi G, Alvarez MG, Cooley G, Viotti R, et al. Changes in Trypanosoma cruzi-specific immune responses after treatment: surrogate markers of treatment efficacy. Clin Infect Dis 2009;49:1675-84.

145. Piacenza L, Alvarez MN, Peluffo G, Radi R. Fighting the oxidative assault: the Trypanosoma cruzi journey to infection. Curr Opin Microbiol 2009;12:415-21.

146. Wen JJ, Dhiman M, Whorton EB, Garg NJ. Tissue-specific oxidative imbalance and mitochondrial dysfunction during Trypanosoma cruzi infection in mice. Microbes Infect 2008;10:1201-9.

147. Báez AL, Lo Presti MS, Rivarola HW, Pons P, Fretes R, PagliniOliva P. Trypanosoma cruzi: cardiac mitochondrial alterations produced by different strains in the acute phase of the infection. Exp Parasitol 2008;120:397-402.

148. Ribeiro CM, Budni P, Pedrosa RC, Farias MS, Parisotto EB, Dalmarco EM, et al. Antioxidant therapy attenuates oxidative insult caused by benzonidazole in chronic Chagas' heart disease. Int J Cardiol 2010;145:27-33.

149. Wen JJ, Bhatia V, Popov VL, Garg NJ. Phenyl-alpha-tert-butyl nitrone reverses mitochondrial decay in acute Chagas' disease. Am J Pathol 2006;169:1953-64.

150. Giordano FJ. Oxygen, oxidative stress, hypoxia, and heart failure. J Clin Invest 2005;115:500-8.

151. de Oliveira TB, Pedrosa RC, Filho DW. Oxidative stress in chronic cardiopathy associated with Chagas' disease. Int J Cardiol 2007;116:357-63.

152. Gupta S, Dhiman M, Wen JJ, Garg NJ. ROS signalling of inflammatory cytokines during Trypanosoma cruzi infection. Adv Parasitol 2011;76:153-70.

153. Dalle-Donne I, Rossi R, Colombo R, Giustarini D, Milzani A. Biomarkers of oxidative damage in human disease. Clin Chem 2006;52:601-23.

154. Giustarini D, Dalle-Donne I, Tsikas D, Rossi R, Giustarini D. Oxidative stress and human diseases: origin, link, measurement, mechanisms, and biomarkers. Crit Rev Clin Lab Sci 2009;46:241-81. 
155. Maçao LB, Wilhelm Filho D, Pedrosa RC, Pereira A, Backes $P$, Torres MA, et al. Antioxidant therapy attenuates oxidative stress in chronic cardiopathy associated with Chagas' disease. Int J Cardiol 2007;123:43-9.

156. Palhares PE, Marcondes NS, Fontana Júnior P, Schaeffer GM, Bastos OM. Correlation between tissue damage and malondialdehydemia in mice infected with Trypanosoma cruzi. Braz J Med Biol Res 1987;20:795-8.

157. Palhares PE, Marcondes NS, Fontana Júnior P, Schaeffer GM, Bastos OM. Malondialdehydemia and parasitemia during acute phase of experimental Chagas' disease in mice. Braz J Med Biol Res 1987;20:799-801.

158. Palhares PE, Fontana Júnior P, Schaffer GM, Marcondes NS, Vergara M. Tissue damage markers in experimental Chagas' disease. Braz J Med Biol Res 1988;21:957-9.

159. Wen JJ, Vyatkina G, Garg N. Oxidative damage during chagasic cardiomyopathy development: role of mitochondrial oxidant release and inefficient antioxidant defense. Free Radic Biol Med 2004;37:1821-33.

160. Michowitz Y, Kisil S, Guzner-Gur H, Rubinstein A, Wexler D, Sheps $D$, et al. Usefulness of serum myeloperoxidase in prediction of mortality in patients with severe heart failure. Isr Med Assoc J 2008;10:884-8.

161. Dhiman M, Estrada-Franco JG, Pando JM, Ramirez-Aguilar FJ, Spratt $\mathrm{H}$, Vazquez-Corzo S, et al. Increased myeloperoxidase activity and protein nitration are indicators of inflammation in patients with Chagas' disease. Clin Vaccine Immunol 2009;16:660-6.

162. Munoz Saravia SG. Chronische Chagas-Erkrankung. Dissertation 2010, Berlin. Available from: http://www.diss.fu-berlin. de/diss/receive/FUDISS_thesis_000000015711. Accessed on 24 September 2012.

163. Wen JJ, Yachelini PC, Sembaj A, Manzur RE, Garg NJ. Increased oxidative stress is correlated with mitochondrial dysfunction in chagasic patients. Free Radic Biol Med 2006;41:270-6.

164. Pérez-Fuentes R, Guégan JF, Barnabé C, López-Colombo A, Salgado-Rosas H, Torres-Rasgado E, et al. Severity of chronic Chagas disease is associated with cytokine/antioxidant imbalance in chronically infected individuals. Int J Parasitol 2003;33:293-9.

165. Pérez-Fuentes R, Torres-Rasgado E, Salgado-Rosas H, Zamora-Ginez I, Sánchez-Guillén MC. The anti-oxidant defence response in individuals with the indeterminate form of Chagas disease (American trypanosomiasis). Ann Trop Med Parasitol 2008;102:189-97.

166. Rivera MT, de Souza AP, Moreno AH, Xavier SS, Gomes JA, Rocha MO, et al. Progressive Chagas' cardiomyopathy is associated with low selenium levels. Am J Trop Med Hyg 2002;66:706-12.

167. Piacenza L, Zago MP, Peluffo G, Alvarez MN, Basombrio MA, Radi R. Enzymes of the antioxidant network as novel determiners of Trypanosoma cruzi virulence. Int J Parasitol 2009;39:1455-64.

168. Díaz ML, Solari A, González Cl. Differential expression of Trypanosoma cruzi I associated with clinical forms of Chagas disease: overexpression of oxidative stress proteins in acute patient isolate. J Proteomics 2011;74:1673-82.

169. Yacoub S, Birks EJ, Slavik Z, Henein M. Early detection of myocardial dysfunction in Chagas disease using novel echocardiographic indices. Trans R Soc Trop Med Hyg 2003;97: 528-34.
170. Dubner S, Schapachnik E, Riera AR, Valero E. Chagas disease: state-of-the-art of diagnosis and management. Cardiol J 2008;15:493-504.

171. Bern C, Montgomery SP, Herwaldt BL, Rassi A Jr, Marin-Neto JA, Dantas RO, et al. Evaluation and treatment of Chagas disease in the United States: a systematic review. J Am Med Assoc 2007;298:2171-81.

172. Viotti RJ, Vigliano C, Laucella S, Lococo B, Petti M, Bertocchi G, et al. Value of echocardiography for diagnosis and prognosis of chronic Chagas disease cardiomyopathy without heart failure. Heart 2004;90:655-60.

173. Acuatella H. Echocardiography in Chagas heart disease. Circulation 2007;115:1124-31.

174. Shehata ML, Turkbey EB, Vogel-Claussen J, Bluemke DA. Role of cardiac magnetic resonance imaging in assessment of nonischemic cardiomyopathies. Top Magn Reson Imaging 2008;19:43-57.

175. Tanowitz HB, Machado FS, Jelicks LA, Shirani J, de Carvalho AC, Spray DC, et al. Perspectives on Trypanosoma cruziinduced heart disease (Chagas disease). Prog Cardiovasc Dis 2009;51:524-39.

176. Carrasco HA, Alarcon M, Olmos L, Burguera J, Burguera M, Dipaolo $A$, et al. Biochemical characterization of myocardial damage in chronic Chagas' disease. Clin Cardiol 1997;20:865-9.

177. Alarcón-Corredor OM, Carrasco-Guerra H, Ramírez de Fernández M, León W. Serum enzyme pattern and local enzyme gradients in chronic chagasic patients. Acta Cient Venez 2002;53:210-7.

178. Shen W, Spindler M, Higgins MA, Jin N, Gill RM, Bloem LJ, et al. The fall in creatine levels and creatine kinase isozyme changes in the failing heart are reversible: complex post-transcriptional regulation of the components of the CK system. J Mol Cell Cardiol 2005;39:537-44.

179. Teixeira PC, Santos RH, Fiorelli Al, Bilate AM, Benvenuti LA, Stolf NA, et al. Selective decrease of components of the creatine kinase system and ATP synthase complex in chronic Chagas disease cardiomyopathy. PLoS Negl Trop Dis 2011;5: e1205.

180. Sturk A, Sanders GT. Macro enzymes: prevalence, composition, detection and clinical relevance. J Clin Chem Clin Biochem 1990;28:65-81.

181. Maisel A, Mueller C, Adams K, Anker SD, Aspromonte N, Cleland JG, et al. State of the art: using natriuretic peptide levels in clinical practice. Eur J Heart Fail 2008;10:824-39.

182. Piazza LA, de Bold AJ, Santamarina N, Hliba E, Rubiolo ER. Atrial natriuretic factor in experimental acute Chagas' disease. Parasitol Res 1994;80:78-80.

183. Puyó AM, Scaglione J, Auger S, Cavallero S, Donoso AS, Dupuy $\mathrm{HA}$, et al. Atrial natriuretic factor as marker of myocardial compromise in Chagas' disease. Regul Pept 2002;105:139-43.

184. Ribeiro AL, dos Reis AM, Barros MV, de Sousa MR, Rocha AL, Perez AA, et al. Brain natriuretic peptide and left ventricular dysfunction in Chagas' disease. Lancet 2002;360:461-2.

185. Talvani A, Rocha MO, Cogan J, Maewal P, de Lemos J, Ribeiro AL, et al. Brain natriuretic peptide and left ventricular dysfunction in chagasic cardiomyopathy. Mem Inst Oswaldo Cruz 2004;99:645-9.

186. Talvani A, Rocha MO, Cogan J, Maewal P, de Lemos J, Ribeiro AL, et al. Brain natriuretic peptide measurement in Chagas heart disease: marker of ventricular dysfunction and arrhythmia. Int J Cardiol 2005;100:503-4. 
187. Melo RB, Parente GB, Victor EG. Measurement of human brain natriuretic peptide in patients with Chagas disease. Arq Bras Cardiol 2005;84:137-40.

188. Vilas-Boas F, Feitosa GS, Soares MB, Pinho-Filho JA, Nascimento $T$, Barojas MM, et al. Invasive and noninvasive correlations of B-type natriuretic peptide in patients with heart failure due to Chagas cardiomyopathy. Congest Heart Fail 2008;4:121-6.

189. Marques DS, Canesin MF, Barutta Júnior F, Fuganti CJ, Barretto AC. Evaluation of asymptomatic patients with chronic Chagas disease through ambulatory electrocardiogram, echocardiogram and B-Type natriuretic peptide analyses. Arq Bras Cardiol 2006;87:336-43.

190. Heringer-Walther S, Moreira MC, Wessel N, Saliba JL, SilviaBarra J, Pena JL, et al. Brain natriuretic peptide predicts survival in Chagas' disease more effectively than atrial natriuretic peptide. Heart 2005;91:385-7.

191. Moreira Mda C, Heringer-Walther S, Wessel N, Moreira Ventura T, Wang Y, Schultheiss HP, et al. Prognostic value of natriuretic peptides in Chagas' disease: a 3-year follow-up investigation. Cardiology 2008;110:217-5.

192. Ribeiro AL, Teixeira MM, Reis AM, Talvani A, Perez AA, Barros $M V$, et al. Brain natriuretic peptide based strategy to detect left ventricular dysfunction in Chagas disease: a comparison with the conventional approach. Int J Cardiol 2006;109:34-40.

193. Sousa L, Botoni FA, Britto RR, Rocha MO, Teixeira AL Jr, Teixeira MM, et al. Six-minute walk test in Chagas cardiomyopathy. Int J Cardiol 2008;125:139-41.

194. Lima MM, Nunes MC, Rocha MO, Beloti FR, Alencar MC, Ribeiro AL. Left ventricular diastolic function and exercise capacity in patients with Chagas cardiomyopathy. Echocardiography 2010;27:519-24.

195. Oliveira BM, Botoni FA, Ribeiro AL, Pinto AS, Reis AM, Nunes Mdo C, et al. Correlation between BNP levels and Doppler echocardiographic parameters of left ventricle filling pressure in patients with Chagasic cardiomyopathy. Echocardiography 2009;26:521-7.

196. Garcia-Alvarez A, Sitges M, Pinazo MJ, Regueiro-Cueva A, Posada E, Poyatos S, et al. Chagas cardiomyopathy: the potential of diastolic dysfunction and brain natriuretic peptide in the early identification of cardiac damage. PLoS Negl Trop Dis 2010;4. pii:e826.

197. Lima-Costa MF, Cesar CC, Peixoto SV, Ribeiro AL. Plasma B-type natriuretic peptide as a predictor of mortality in communitydwelling older adults with Chagas disease: 10-year followup of the Bambui Cohort Study of Aging. Am J Epidemiol 2010;172:190-6.
198. Fernandes F, Dantas S, Ianni BM, Ramires FJ, Buck P, Salemi VM, et al. Leptin levels in different forms of Chagas' disease. Braz J Med Biol Res 2007;40:1631-6.

199. Barbosa MM, Nunes Mdo C, Ribeiro AL, Barral MM, Rocha MO. $\mathrm{N}$-terminal proBNP levels in patients with Chagas disease: $\mathrm{a}$ marker of systolic and diastolic dysfunction of the left ventricle. Eur J Echocardiogr 2007;8:204-12.

200. Mady C, Fernandes F, Arteaga E, Ramires FJ, Buck Pde C, Salemi VM, et al. Serum NT pro-BNP: relation to systolic and diastolic function in cardiomyopathies and pericardiopathies. ArQ Bras Cardiol 2008;91:46-50.

201. Scirica BM, Morrow DA. Troponins in acute coronary syndromes. Prog Cardiovasc Dis 2004;47:177-88.

202. Mingels A, Jacobs L, Michielsen E, Swaanenburg J, Wodzig W, van Dieijen-Visser M. Reference population and marathon runner sera assessed by highly sensitive cardiac troponin $\mathrm{T}$ and commercial cardiac troponin T and I assays. Clin Chem 2009;55:101-8.

203. Jaffe AS. Elevation in cardiac troponin measurements: false false-positives. Cardiovasc Toxicol 2001;1:87-92.

204. Jeremias A, Gibson CM. Narrative review: alternative causes for elevated cardiac troponin levels when acute coronary syndromes are excluded. Ann Intern Med 2005;142:786-91.

205. Schulz O, Kirpal K, Stein J, Bensch R, Berghöfer G, Schimke I, et al. Importance of low concentrations of cardiac troponins. Clin Chem 2006;52:1614-5.

206. Saravia SG, Knebel F, Schroeckh S, Ziebig R, Lun A, Weimann $A$, et al. Cardiac troponin T release and inflammation demonstrated in marathon runners. Clin Lab 2010;56:51-8.

207. Basquiera AL, Capra R, Omelianiuk M, Amuchástegui M, Madoery RJ, Salomone OA. Serum troponin T in patients with chronic Chagas disease. Rev Esp Cardiol 2003;56:742-4.

208. Arias R, Bastos C, Mota G, Sodré F, Moreira A, Tavares A, et al. Troponin in Chagas disease. Braz J Infect Dis 2003;7:358-9.

209. Machado MN, Suzuki FA, Mouco OC, Hernandes ME, Lemos MA, Maia LN. Positive troponin T in a chagasic patient with sustained ventricular tachycardia and no obstructive lesions on cine coronary angiography. Arq Bras Cardiol 2005;84: 182-4.

210. Muñoz-Saravia SG, Haberland A, Wallukat G, Schimke I. Chronic Chagas' heart disease: a disease on its way to becoming a worldwide health problem: epidemiology, etiopathology, treatment, pathogenesis and laboratory medicine. Heart Fail Rev 2012;17:45-64. 


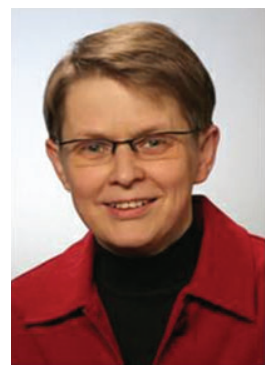

Annekathrin Haberland studied Pharmacy and received her PhD degree in 1990 at the Humboldt-Universität zu Berlin. After a postdoc period at the Institut für Pathologische und Klinische Biochemie der Humboldt-Universität zu Berlin, she did research for a couple of years at the Max-Delbrück-Centrum für Molekulare Medizin, Berlin-Buch. After joining the department of Medizinische Chemie und Pathobiochemie der Charité - Universitätsmedizin Berlin, her research fields are: studies on the pathogenic impact in the heart and circulatory system of agonistic-like autoantibodies directed against G-protein coupled receptors, the development of assays for their measurement and the introduction of strategies for the autoantibody removal or neutralization mainly in patients with cardiomyopathy. Annekathrin Haberland, together with Gerd Wallukat and Ingolf Schimke, participated in the introduction of the first aptamers for specific binding and neutralizing of G-protein coupled receptor autoantibodies.

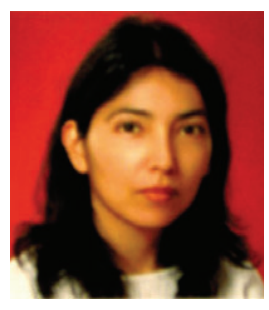

Silvia Gilka Munoz Saravia studied Biochemistry and Pharmacy at the Mayor Real y Pontificia de San Francisco Xavier de Chuquisaca University, Sucre, Bolivia, followed by the postgraduate master study for "Laboratory diagnostics of infectious diseases" at the Andina Simón Bolivar University, Sucre, Bolivia. She received her Master degree in 2007. From 2007 to 2009, she was PhD student at Charité - Universitätsmedizin Berlin, financed by the HelmutBreuer-Stipendium of the Deutsche Gesellschaft für Klinische Chemie und Laboratoriumsmedizin and received her PhD in 2010.

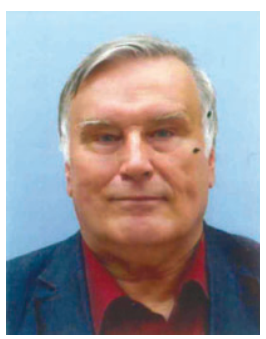

Gerd Wallukat studied Biology at the Humboldt-Universität zu Berlin and Karl-Marx-Universität Leipzig. After joining the Institut für Herz-Kreislauf-Forschung der Akademie der Wissenschaften der Deutschen Demokratischen Republik, he started his research on G-protein coupled receptors and their interaction with the respective autoantibodies. He received his PhD degree in 1978. He was the first describer of agonistic-like autoantibodies directed against the $\beta 1$-receptor in patients with dilated cardiomyopathy and myocarditis. Agonistic-like autoantibodies against G-protein coupled receptors and their pathogenic consequences in the heart and circulatory diseases have always been in the focus of Gerd Wallukat's research which he continued after 1990 in the Max-Delbrück-Centrum für Molekulare Medizin. Gerd Wallukat developed a functional bioassay for the identification and characterization of the autoantibodies and was involved in the first immunoadsorption studies to remove the autoantibodies from patients' sera. Currently, he is engaged in the introduction of a new treatment strategy using aptamers for the autoantibodies binding and neutralization in cardiovascular diseases.

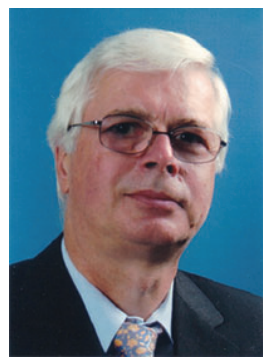

Reinhard Ziebig studied Chemistry at the Humboldt-Universität zu Berlin and received his PhD degree in 1979. After joining the Institut für Pathologische und Klinische Biochemie der HumboldtUniversität zu Berlin, he trained in Clinical Chemistry and received his state certificate as a Clinical Chemist in 1986. He is a European Clinical Chemist and possesses the competence of the Deutsche Vereinte Gesellschaft für Klinische Chemie und Laboratoriumsmedizin for postgraduate education in Clinical Chemistry. He is presently scientific officer of the Labor Berlin $\mathrm{GmbH}$. His research is focused on heart markers and their interaction with kidney impairment. 


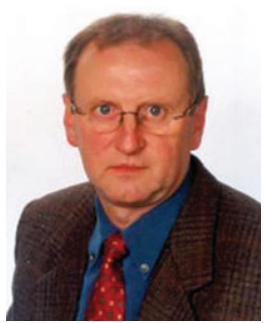

Ingolf Schimke studied Chemistry and Biochemistry at the ErnstMoritz-Arndt-Universität Greifswald. He received his PhD degree in 1977 at the Akademie der Wissenschaftern der Deutschen Demokratischen Republik. After postgraduate training in Clinical Chemistry at the Humboldt-Universität zuBerlin, he received his state certificate as a Clinical Chemist. He is a European Clinical Chemist, Professor of Clinical Chemistry and Laboratory Medicine and head of the department of Medizinische Chemie und Pathobiochemie, Charité - Universitätsmedizin Berlin. He is presently chair of the commission for postgraduate education of the Deutsche Vereinte Gesellschaft für Klinische Chemie und Laboratoriumsmedizin. His research is focused on the pathological and clinical chemistry of the heart and circulatory diseases with special emphasis on ischemia, oxidative stress and inflammation as pathogenic drivers. Presently, he studies the pathogenic impact and measurement of agonistic-like autoantibodies against G-protein coupled receptors in heart and circulatory diseases and the development of treatment strategies for the binding and neutralization of autoantibodies using specific aptamers. 